\title{
REVIEW
}

\section{The relationship between subtypes of depression and cardiovascular disease: a systematic review of biological models}

\author{
BT Baune ${ }^{1}$, M Stuart ${ }^{2}$, A Gilmour ${ }^{2}$, H Wersching ${ }^{3}$, W Heindel ${ }^{4}$, V Arolt ${ }^{5}$ and K Berger ${ }^{3}$
}

A compelling association has been observed between cardiovascular disease (CVD) and depression, suggesting individuals with depression to be at significantly higher risk for CVD and CVD-related mortality. Systemic immune activation, hypothalamicpituitary-adrenal (HPA) axis hyperactivity, arterial stiffness and endothelial dysfunction have been frequently implicated in this relationship. Although a differential epidemiological association between CVD and depression subtypes is evident, it has not been determined if this indicates subtype specific biological mechanisms. A comprehensive systematic literature search was conducted using PubMed and PsycINFO databases yielding 147 articles for this review. A complex pattern of systemic immune activation, endothelial dysfunction and HPA axis hyperactivity is suggestive of the biological relationship between CVD and depression subtypes. The findings of this review suggest that diagnostic subtypes rather than a unifying model of depression should be considered when investigating the bidirectional biological relationship between CVD and depression. The suggested model of a subtype-specific biological relationship between depression and CVDs has implications for future research and possibly for diagnostic and therapeutic processes.

Translational Psychiatry (2012) 2, e92; doi:10.1038/tp.2012.18; published online 13 March 2012

\section{Introduction}

The association between cardiovascular disease (CVD) and depression is well established and is suggested to be bidirectional. Numerous clinical and epidemiological studies investigating the association of depression and CVD have suggested that depression independently increases the risk of CVD 1.5-fold on average, and that patients with coronary artery disease and depression have a two- to threefold increased risk of future non-fatal and fatal cardiac events compared with those cardiac patients without depression. ${ }^{1-4}$ Biological mechanisms that might link these two conditions together include the hypothalamic-pituitary-adrenal (HPA) axis, pro-inflammatory cytokines, changes of arterial elasticity and endothelial function (for reviews see refs 1,4-14).

Many epidemiological and clinical studies examining biological models of the relationship between CVD and depression have classified depression dichotomously either as yes/no or restricted analyses to major depression (MD) only. However, more recent research has begun to differentiate depressive subtypes such as dysthymia, melancholic MD (MMD), MD with typical or atypical features (see description of subtypes in Diagnostic and Statistical Manual of Mental Disorders, Fourth Edition, Text Revision (DSM-IVTR); American Psychiatric Association ${ }^{15}$ ). Although differences in the strength of the association between various depression subtypes and CVD have been demonstrated, ${ }^{16-27}$ it remains unclear if these subtype-specific associations are caused by a subtype-specific biological mechanism. Surprisingly, studies directly addressing this question are lacking. If this assumption would be true one would expect firstly that subtypes of depression are characterized by specific biological models and secondly that these specific models are also relevant for the pathogenesis of CVD.

The aim of this review is to identify biological models and correlates of subtypes of depression that might be involved in the relationship with CVD. This review proposes a differential subtype model of depression relevant for the association with CVD as opposed to a unifying model of depression that is commonly used in the literature on CVD and depression comorbidity.

The literature search for this review was carried out according to the PRISMA (preferred reporting items for systematic reviews and meta-analyses) guidelines as they apply to systematic reviews. ${ }^{28} \mathrm{~A}$ systematic literature search was performed using the PubMed and PsycINFO databases covering articles from 1969-2011. The following search terms were used: (dysthymi* or (subsyndromal and depression) or (minor and depression) or (subthreshold and depression)) or bipolar disorder (BD) or MD or melanchol ${ }^{\star}$ or (depressi* and (melanchol* or atypical or psycho* or vascular)) and (immune

\footnotetext{
${ }^{1}$ Discipline of Psychiatry, School of Medicine, University of Adelaide, Adelaide, SA, Australia; ${ }^{2}$ Discipline of Psychiatry, School of Medicine, James Cook University, Townsville, QLD, Australia; ${ }^{3}$ Institute of Epidemiology and Social Medicine, University of Muenster, Muenster, Germany; ${ }^{4}$ Institute of Clinical Radiology, University Hospital Muenster, Muenster, Germany and ${ }^{5}$ Department of Psychiatry and Psychotherapy, University of Muenster, Muenster, Germany Correspondence: Professor BT Baune, Discipline of Psychiatry, School of Medicine, University of Adelaide, Adelaide, SA 5005, Australia. E-mail: bernhard.baune@ adelaide.edu.au Keywords: biological mechanisms; cardiovascular disease; endothelial dysfunction; inflammation; subtypes of depression Received 31 January 2012; accepted 4 February 2012
} 
or inflamm* or cytokine or glucocorticoid or cortisol or hypothalamus or endothelium or coag* or clotting or thrombosis). A second search was conducted as above, but with the addition of the following: and (CVD or stroke or ischemic heart disease or myocardial infarction or coronary heart disease or arterial stiffness or atherosclerosis). Articles were also obtained by reviewing reference lists of review and research articles. A total of 736 studies were found using these search terms. A total of 371 articles remained after assessment of abstracts for relevance to the aims of this review. Of these, 224 studies were excluded after review of the full text if they did not directly compare between subtypes of depression, did not provide data for individual subtypes, included child/adolescent populations or did not include measurement of relevant biomarkers. In most cases cross-sectional studies were also excluded; however, where studies of a longitudinal design were not available then cross-sectional studies were retained. In all, 147 studies were included in the final review (Figure 1).

\section{The bidirectional relationship between depression and CVD}

The relationship between depression and CVD has been proposed to be bidirectional; existing depression increases the risk of incident CVD and a history of CVD increases the risk of depression. Many prospective and retrospective studies have investigated the association of existing depression and incident CVD. ${ }^{29-39}$ Several meta-analyses of these studies have demonstrated a significant positive correlation with a moderate effect size of 1.5-2.7..$^{3,40-42}$

Similarly, several studies have investigated the role of depression status as a prognostic factor in patients with existing CVD. ${ }^{43-50}$ Meta-analysis of these studies suggests that depressed patients have a 1.6-2.7-fold increased risk for further cardiovascular events within 24 months. ${ }^{42,51-53}$ Conversely, relatively few studies have investigated the role of existing CVD in increasing the risk for the onset of depression (Supplementary Table). ${ }^{39,43,54}$ To our knowledge, this data has not been subjected to meta-analysis.

Analysis of the association between CVD and subtypes of depression reveals that the relationship with CVD appears to be particularly strong in patients with dysthymic disorder, ${ }^{16,18,19,23}$ and BDs. ${ }^{16,17,22,27}$ However, this literature

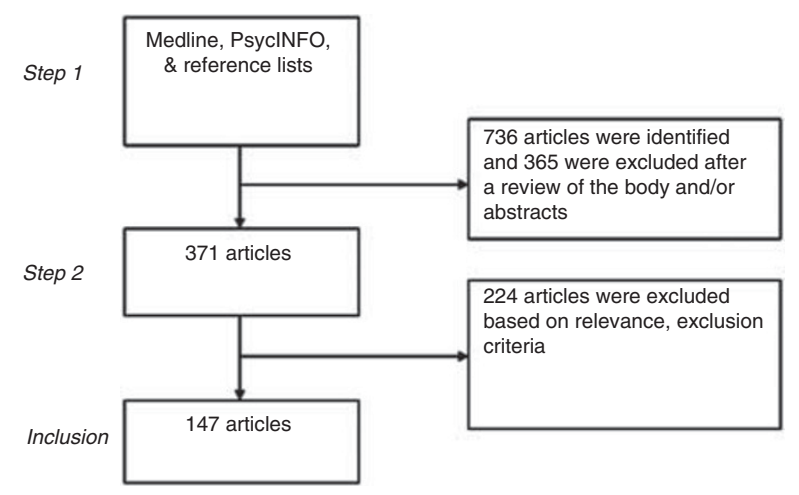

Figure 1 Study inclusion flowchart. is significantly limited by the paucity of prospective studies and studies that investigate a larger range of subtypes of depression (Table 1).

In addition to its association with CVD, depression is also significantly associated with several other major cardiac risk factors including smoking, obesity and diabetes. ${ }^{55,56}$ Many studies, however, have demonstrated that depression remains independently associated with CVD even after adjusting for these risk factors. This suggests that there are other mediators of this relationship including both biological and behavioral mediators. ${ }^{2,55}$

\section{Biological mechanisms involved in the CVD-depression association}

The relationship between depression and CVD has been proposed to be bidirectional; that is, existing depression increases the risk of incident CVD and a history of CVD increases the risk of depression. Many prospective and retrospective studies have investigated the association of existing depression and incident CVD. ${ }^{29-39}$ Several metaanalyses of these studies have demonstrated a significant positive correlation with a moderate effect size of 1.5-2.7. .,40-42 $^{-4}$ Similarly, several studies have investigated the role of depression status as a prognostic factor in patients with existing CVD. ${ }^{43-50}$ Meta-analysis of these studies suggests that depressed patients have a 1.6-2.7-fold increased risk for further cardiovascular events within 24 months. ${ }^{42,51-53}$ Conversely, relatively few studies have investigated the role of existing CVD in increasing the risk for the onset of depression. ${ }^{39,43,54}$ To our knowledge, this data has not been subjected to meta-analysis.

The association with CVD appears to be particularly strong in patients with dysthymic disorder, ${ }^{16,18,19,23}$ and BDs. ${ }^{16,17,22,27}$ However, this literature is significantly limited by the paucity of prospective studies and by studies that investigate a larger range of subtypes of depression.

In addition to its association with CVD, depression is also significantly associated with several major cardiovascular risk factors, including smoking, obesity and diabetes. ${ }^{55}$ Many studies, however, have demonstrated that depression remains independently associated with CVD even after adjusting for these risk factors. This suggests that there are other factors impacting on this relationship, including both biological and behavioral mediators ${ }^{2,55}$ (Figure 2).

Studies investigating immune system functioning in individuals with 'depression', irrespective of depressive subtypes, have found that many of these individuals manifest elevated inflammatory markers, particularly c-reactive protein (CRP), interleukin-6 (IL-6), interleukin-1 $\beta$ (IL-1 $\beta$ ) and tumor necrosis factor- $\alpha$ (TNF- $\alpha){ }^{57,58}$ Several authors have suggested that this association of depression and inflammatory markers may be a key biological link in the comorbidity of depression and CVD (see for reviews refs $1,4,7,10,12,13,59$ ). This may be mediated by interactions of inflammatory signaling cascades with several key processes implicated in the pathogenesis and pathophysiology of CVD. Key among these processes is atherosclerosis. It has been proposed that inflammatory mediators may accelerate the progression of atherosclerosis through several mechanisms, including chemoattraction of 


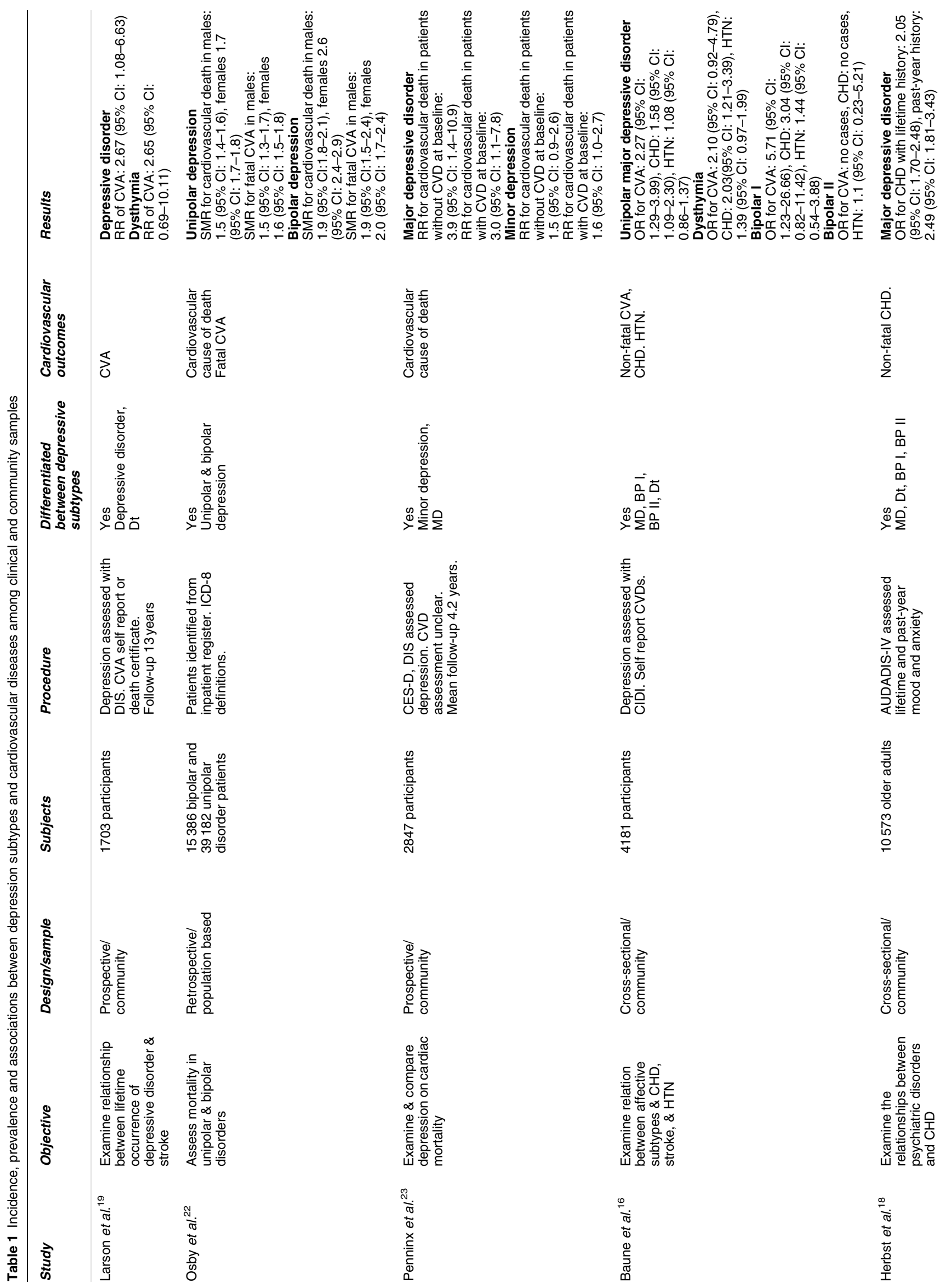




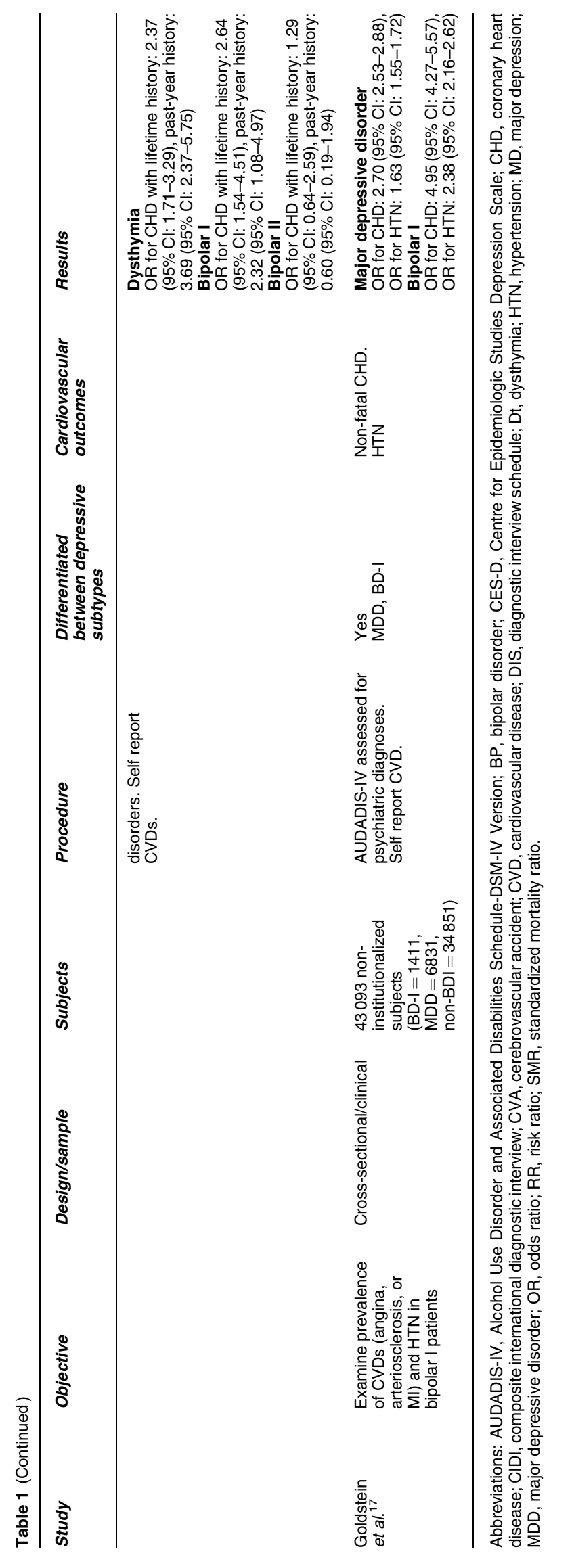

leukocytes to atherosclerotic lesions, inducing endothelial activation and expression of adhesion molecules and stimulating the expression of vascular endothelial growth factors (see for review ref. 60). Furthermore, inflammatory signaling cascades may amplify and accelerate the process of coagulation and thrombus formation. ${ }^{61}$

It has been suggested that the dysfunction of the HPA axis may also contribute to the pathogenesis of depression and comorbid CVD. ${ }^{1,7}$ This contribution may be mediated, at least in part, by the loss of glucocorticoid receptor-mediated negative feedback on inflammatory signaling. It is also worth noting that the disruptions of the HPA axis may be reciprocally regulated by altered expression of pro-inflammatory cytokines constituting a complex bidirectional biological crosstalk. ${ }^{62}$ Dysregulation of the HPA axis may also lead to sympathoadrenal hyperactivity via central pathways. This hyperactivity may lead to an increase in vasoconstrictive tone, heart rate and platelet activation each of which have been implicated in the progression to CVD. ${ }^{7,63}$ Furthermore, excess sympathetic drive may result in reduced heart rate variability, which may increase vulnerability to arrhythmia. ${ }^{64}$

Endothelial dysfunction is a recognized risk factor for CVD that is also often observed in patients with depression. ${ }^{65-68}$ In both 'healthy' young volunteers and patients with CVD, depression status was associated with attenuated arterial dilatory responses to flow and nitroglycerin in addition to an increased expression of endothelial adhesion molecules and chemokines. $^{69,70}$ These factors may function to predispose these patients to atherosclerosis, thrombosis and vasospasm.

\section{Biological mechanisms in depression subtypes relevant to CVD-depression comorbidity}

More recent research has begun to investigate immune activation among depressed patients according to depression subtype, which might help to improve the understanding of the biological mechanisms underlying the relationship between CVD and depression.

MMD. Much research over the last decades has investigated whether the subtype of MMD may have a separate underlying pathophysiology to other non-melancholic forms of MD (NMMD) (Table 2a). Particularly relevant to CVDs are the investigation of immune alterations in MMD.

Many studies have investigated the profile of pro-inflammatory cytokines expressed in MMD as compared with NMMD; however, no consistent pattern has emerged. Of the pro-inflammatory cytokines IL-1 $\beta$ has been the most frequently investigated. Studies of serum IL-1 $\beta$ have variously reported increased, ${ }^{71}$ decreased ${ }^{72}$ or non-significantly different $^{73,74}$ levels in MMD relative to NMMD. Similarly, study of ex-vivo lipopolysaccharide stimulated whole blood IL-1 $\beta$ production have produced equivocal results. ${ }^{75}$ Other aspects of the IL-1 system have seldom been investigated, however, one study did report a decrease in the ratio of serum IL-1 receptor antagonist to IL-1 $\beta$ in NMMD compared with MMD, which normalized in clinical remission. ${ }^{72}$

Study of the cytokines IL- 6 and TNF- $\alpha$ have also produced mixed results in similar investigations. No significant 


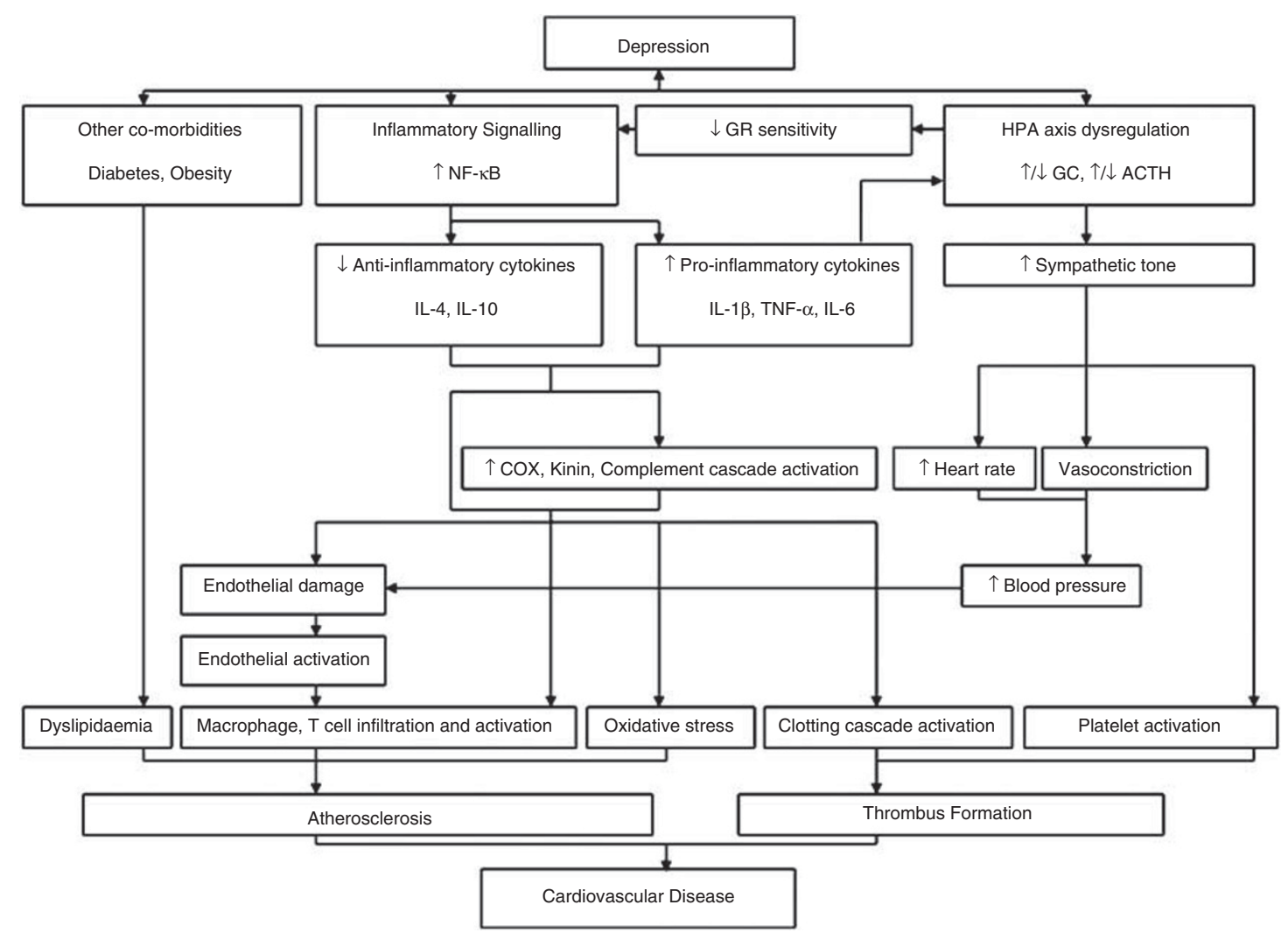

Figure 2 Biological mechanisms for the bidirectional relationship between depression and CVD.

difference between MMD and NMMD was reported in serum; ${ }^{74}$ however, a study of ex-vivo mitogen-stimulated peripheral blood mononuclear cells did demonstrate an increase in IL-6 production in MMD relative to both NMMD and controls. ${ }^{21}$ There is also poor evidence of increased serum TNF- $\alpha$ in MMD relative to NMMD as reported by one study, ${ }^{73}$ yet others have found no significant difference in serum. ${ }^{71}$

In addition further aspects of the inflammatory response have also been investigated in MMD, including the acute phase proteins: CRP, haptoglobin and transferrin, and $\alpha-2-$ macroglobulin. Of these factors, CRP has been found to be elevated in NMMD relative to MMD and controls, whereas $\alpha-2$ macroglobulin was higher in MMD relative to NMMD and controls. ${ }^{75}$ Haptoglobin and transferrin were found to be higher in both MMD and NMMD relative to controls but did not significantly vary between depressive groups. ${ }^{21}$ In contrast with these results, others have reported that serum haptoglobin was significantly higher in patients with MMD than NMMD, ${ }^{76}$ or else not different between MMD, NMMD or controls. ${ }^{75}$ Taken together, these consistently contradictory results in both pro-inflammatory cytokines and acute phase proteins suggest that the inflammatory system is unlikely to be differentially disordered in MMD as compared with NMMD.

Several authors have compared indices of adaptive immunity in MMD and NMMD. One study suggests an impairment of Th1-mediated immunity in MMD as these patients demonstrated reduced mitogen-stimulated whole blood IL-2 and interferon gamma (IFN- $\gamma$ ) production relative to both NMMD and controls at the untreated baseline. ${ }^{24}$ Other studies, however, have demonstrated an increase in the Th1 marker neopterin in serum relative to $\mathrm{NMMD},{ }^{73}$ and no significant difference in constitutive serum levels of the Th1 cytokine IFN- $\gamma \cdot{ }^{74}$ A contrasting result has also been reported for IL-2 where MMD had greater ex-vivo peripheral blood mononuclear cell mitogen-stimulated production of IL-2 relative to NMMD and controls. ${ }^{77}$ This discrepancy from the earlier result may be explained by the reduction in absolute lymphocyte numbers observed in MMD patients in that study-thereby confounding the result in whole blood. ${ }^{24}$ In contrast to the Th1 cytokines no significant differences have been reported in the Th2 cytokines IL-4 and IL-10. 24,71,77

Alterations in cell population numbers have also been observed in MMD relative to NMMD. One group noted an increase in the absolute CD4 + cell count in addition to an increased CD4 + :CD8 + ratio that was not altered in clinical remission. This was not accompanied by any changes in absolute CD8 + cell count or other T-cell populations when comparing MMD and NMMD patients although natural killer cell activity was reduced in NMMD patients and significantly negatively correlated with depression severity. ${ }^{77}$ Another group reported an increased absolute monocyte count in NMMD relative to both $\mathrm{MMD}$ and controls, ${ }^{75}$ and the same group found no significant difference in absolute natural killer cell count between MMD and NMMD although the depressed groups were significantly higher than controls. ${ }^{24}$

HPA axis dysfunction has also been assessed as a potential differential biological marker for MMD. Several decades of studies utilizing the dexamethasone (DEX) 


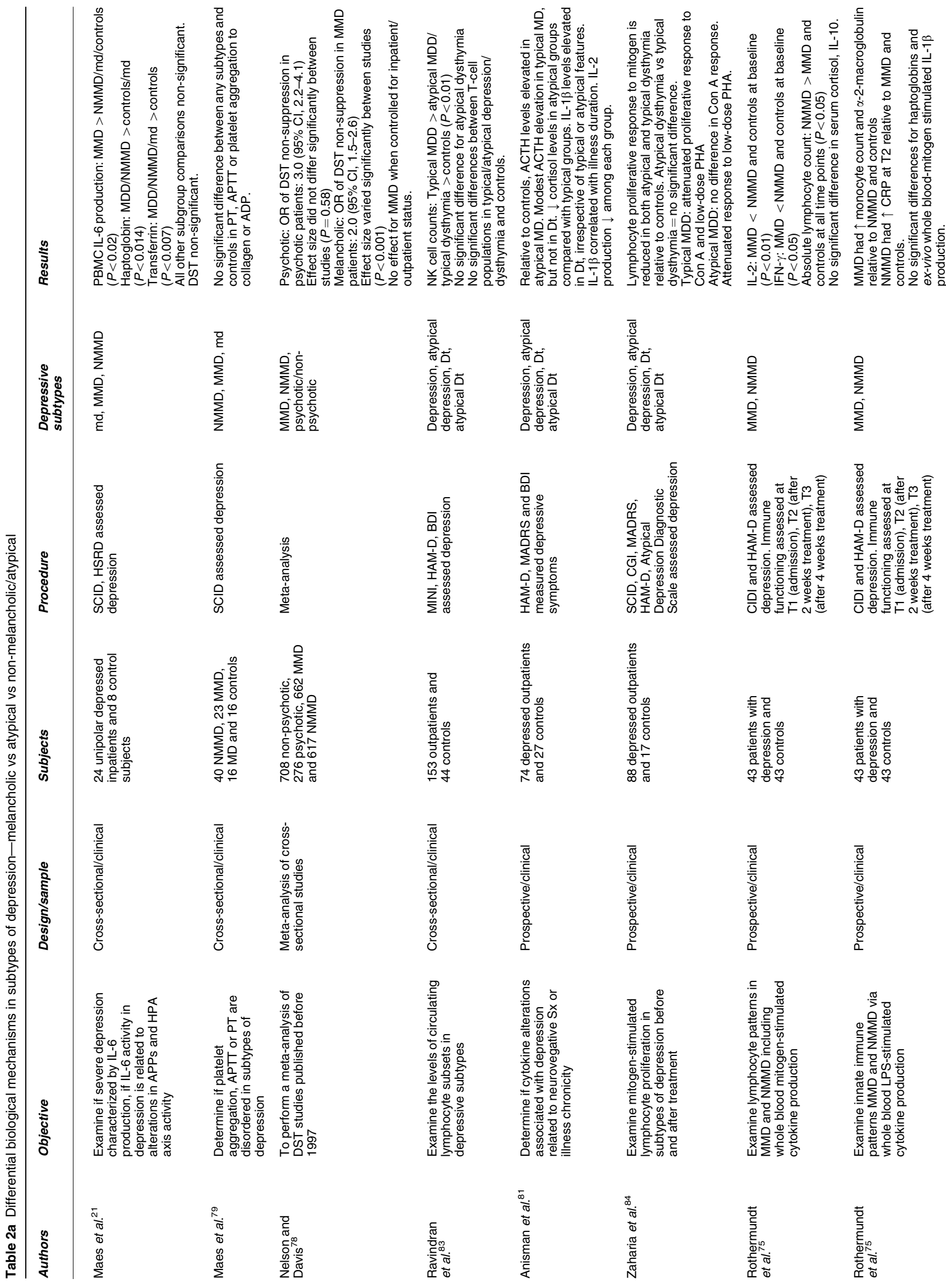




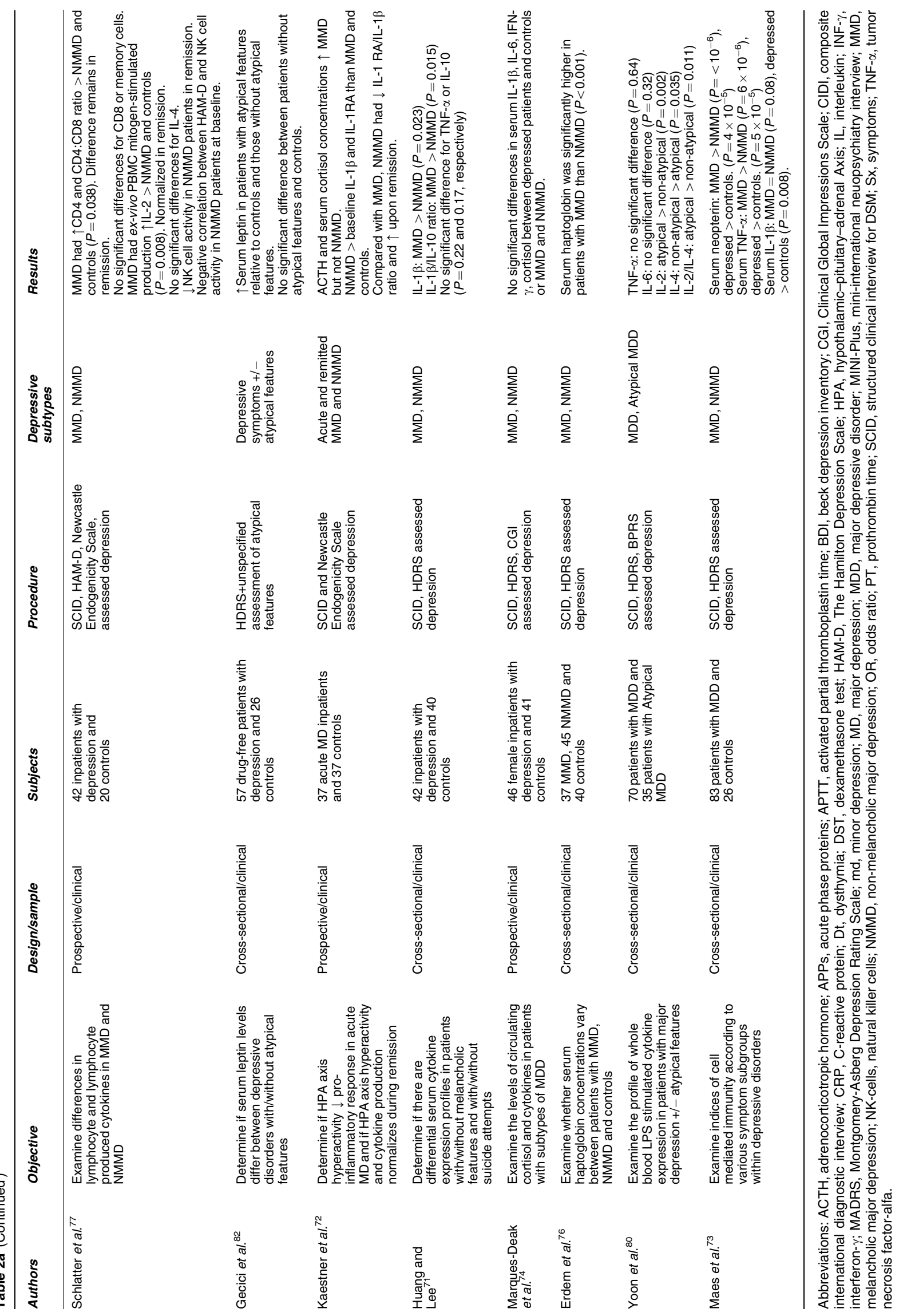


suppression test as a potential discriminator between MMD and NMMD were included in a meta-analysis by Nelson and Davis, ${ }^{78}$ which found that there was no significant difference in rates of DEX suppression test non-suppression between MMD and NMMD after adjustment for inpatient/outpatient status. Other measures of HPA axis function such as serum adrenocorticotrophic hormone (ACTH) or cortisol have occasionally been reported in elevated levels in MMD as compared with NMMD, ${ }^{72}$ however, the majority of studies report no significant difference. ${ }^{21,24,74}$

It is also of particular relevance to note that a small study found no significant difference between MMD, NMMD, 'minor depression' or controls in regards to several indices of coagulation; prothrombin time, activated partial thromboplastin time and platelet aggregation to collagen or adenosine diphosphate. $^{79}$

Atypical depression. Relatively few studies have assessed differentially disordered biomarkers in atypical depression. A study of whole blood lipopolysaccharide stimulated cytokine production found that patients with atypical depression expressed more IL-2 and less IL-4 resulting in an overall increased IL-2:IL-4 ratio as compared with typical depression. The same study found no significant difference for TNF- $\alpha$ or IL-6. ${ }^{80}$ Such a report would suggest a Th1 shift in the basal immune state associated with atypical depression relative to typical depression. Another study of mitogen-stimulated peripheral blood mononuclear cells found no significant difference in IL-1 $\beta$ or IL-2 production between the atypical and typical depressive subtypes. ${ }^{81} \mathrm{~A}$ single report has also identified increased serum leptin as a marker of atypical depression, which was significantly different from both typical depression and controls. ${ }^{82}$ The significance of this result is unclear as it awaits replication.

Some evidence also suggests differentially disordered cell populations in typical compared with atypical depression. Although there appears to be no significant difference in lymphocyte cell counts, ${ }^{83}$ one study found that lymphocyte proliferative response to mitogens differed slightly between the subtypes; typical MD showed an attenuated proliferative response to both concavalin A and low-dose phytohemagglutanin whereas atypical MD showed an attenuated response to phytohemagglutanin only. ${ }^{84}$ The (patho-) physiological significance of this result is questionable. A single report also found natural killer cell counts to be significantly higher in typical MD than atypical MD, which was in turn significantly higher than controls. ${ }^{83}$ Indices of HPA axis dysfunction also do not appear to be differentially disordered between atypical and typical depression ${ }^{81}$ (Table 2a).

Dysthymia. The evidence for a differential biological profile in dysthymia is again inconsistent. Much of this investigation has focused on the pro-inflammatory cytokine IL-1 $\beta$. One group investigated IL-1 $\beta$ in individuals with dysthymia and $\mathrm{MD}$, and distinguished between typical and atypical features for both of these subtypes. Their results suggested that individuals with dysthymia, irrespective of whether typical or atypical features were present, had significantly elevated levels of IL-1 $\beta$ relative to controls. Although typical and atypical dysthymics had higher levels of IL-1 $\beta$ relative to typical and atypical major depressives, the authors did not report if these differences reached statistical significance. Additionally, concentrations of IL-1 $\beta$ increased with phytohemagglutinin dosage among all depressive subtypes but not for controls. Taken together, this study would seem to suggest that dysthymia, but not MD, is characterized by overexpression of IL-1 $\beta$. Moreover, this overexpression was significantly and positively associated with baseline severity scores and duration of illness. ${ }^{81}$

More recent studies have also suggested that dysthymia may be characterized by higher overexpression of IL-1 $\beta$ than MD. In a study by Schlatter et al. the dysthymic group had significantly higher levels of IL-1 $\beta$ relative to controls, and $\sim 30 \%$ higher levels of IL- $1 \beta$ production relative to those with $\mathrm{MD}$, however, this latter difference again did not reach significance. They also reported the absence of any associations between IL-1 $\beta$ and clinical characteristics of dysthymia such as severity or duration of illness. ${ }^{25,26}$ Furthermore, they did not find significant differences in TNF- $\alpha$ expression between any of the depressive subtypes or between dichotomized depression and controls. ${ }^{25}$

These findings are somewhat complicated by those reported by Maes et al. ${ }^{20}$ In their study, Maes et al. found that MD patients had significantly higher IL-1 $\beta$ levels relative to controls, whereas intermediate levels of IL-1 $\beta$ were evident among patients with minor depression (dysthymia, adjustment disorder with depressed mood). However, as with the aforementioned studies, the differences in IL-1 $\beta$ levels between MD and dysthymia for IL-1 $\beta$ levels was not actually significant. However, comparison of these findings is difficult as in Maes et al. dysthymia and adjustment disorder with depressed mood were combined into the category of 'minor depression', and information regarding the duration of depressive symptoms among dysthymic and MD patients was not reported. ${ }^{20}$

These same studies suggest that MD and dysthymia do not differ significantly in the level of overexpression of IL-6. ${ }^{21,25,26}$ A more recent study also found no significant difference between MD and dysthymia in plasma IL-6 or serum brainderived neurotrophic factor. ${ }^{85}$

A recent genotypic analysis of patients with post-stroke depression determined that several polymorphisms were differentially associated with major and minor post-stroke depression. The IL-4 $+33 \mathrm{C} / \mathrm{C}$ genotype was associated with post-stroke MD only, whereas the IL-10-1082A/A genotype was found to be associated with both post-stroke MD and minor depression. ${ }^{86}$

In addition to these investigations of cytokines, a series of studies by Thomas et al. detail the lack any significant differences between MD, controls and 'subsyndromal depression' in serum levels of IL-1 $\beta, \mathrm{CRP}$, intercellular adhesion molecule-1 or vascular cell adhesion molecule-1..$^{87,88}$

Evidence of HPA axis dysfunction in dysthymia is also somewhat inconsistent. One group investigated cortisol levels in samples of patients with MD and minor depression, they found that with DEX and basal cortisol levels as covariates, MD patients had significantly higher post-DEX cortisol levels relative to controls, whereas patients with minor depression had intermediate levels. ${ }^{20}$ However, an earlier study by the same group found no significant difference between any 
subgroups of depression, including dysthymia and their controls. $^{21}$

Little evidence suggests differential derangement of cellular indices in dysthymia. One study found natural killer cell counts to be higher in the atypical/typical subtypes of MD than the atypical/typical subtypes of dysthymia. The same study did not find any difference between MD and dysthymia in lymphocyte populations. ${ }^{83}$ No significant differences between MD and dysthymia were detected on mitogen-induced lymphocyte proliferation assays. ${ }^{84}$

A study investigating the indices of clotting prothrombin time, activated partial thromboplastin time and platelet aggregation to collagen or adenosine diphosphate found no significant difference between patients with minor depression and MD, or between depression groups and controls ${ }^{79}$ (Table 2b).

Psychotic depression. In biomarker studies of the psychotic subtype of depression most attention has concentrated on differential dysregulation of the HPA axis. Meta-analysis of DEX suppression test studies suggests that patients with psychotic depression were significantly more likely to be non-suppressors in response to DEX (odds ratio: 3.0, 95\% confidence interval, 2.2-4.1), ${ }^{78}$ however, DEX suppression test studies published since have continued to report inconsistent results. ${ }^{89,90}$ Other indices of HPA axis functioning have also been shown to discriminate between psychotic and non-psychotic MD. Intensive monitoring of serum cortisol levels suggests that patients with psychotic MD may have a higher mean serum cortisol, ${ }^{91}$ a higher cortisol nadir and higher evening cortisol relative to both patients with non-psychotic MD and controls. ${ }^{92,93}$ However, others have found that the mean serum cortisol and $24 \mathrm{~h}$ cortisol amplitude did not differ between psychotic and non-psychotic MD. ${ }^{89,94}$ Similarly, opposing results for $24 \mathrm{~h} \mathrm{ACTH} \mathrm{levels} \mathrm{have} \mathrm{also}$ been reported. ${ }^{91,94}$ Examination of other hormones in the hypothalamus-pituitary axis have also shown no significant differences between psychotic and non-psychotic MD in assays of thyroid-stimulating hormone response to thyrotrophin-releasing hormone or growth hormone response to growth hormone releasing factor. ${ }^{90}$ These results may be tentatively interpreted to suggest there may be some degree of differential dysregulation in the HPA axis related to the psychotic/non-psychotic distinction within MD.

Other differential mechanisms potentially relevant to CVD have been reported. One study suggests that platelet serotonin was increased in samples from patients with psychotic MD as compared with non-psychotic MD. ${ }^{89}$ Also, plasma dopamine $\beta$-hydroxylase (the enzyme converting dopamine to norepinephrine) activity has been reported to be lower in patients with psychotic relative to non-psychotic $\mathrm{MD}^{95}$ (Table 2c).

BDs. Several studies in patients with BD observed an activation of the immune system during the manic, the depressed or the euthymic states of bipolar illness. Some authors suggested that certain markers may be specific to each state, however, no consistent pattern has emerged as of yet. Several pro-inflammatory cytokines have been investigated in $\mathrm{BD}$. Investigating the ex-vivo mitogen- stimulated cytokine production of peripheral blood mononuclear cells from manic patients with $\mathrm{BD}$, a reduced production of IFN- $\gamma$ was observed that persisted in both acute mania and remission. ${ }^{96}$ These findings were replicated by others, who also observed an increase in plasma levels of $\mathrm{IL}-1$ receptor antagonist, SCD4 and SCD8 in mania. ${ }^{97}$ In contrast, Kim et al. ${ }^{98}$ were unable to replicate the finding of increased IFN- $\gamma$ in a cohort of medication free manic patients, however, they did note an increase in the IFN- $\gamma /$ IL-4 ratio which is purported to be a more valid measure of the proinflammatory activities of IFN- $\gamma$ than IFN- $\gamma$ levels alone.

Other pro-inflammatory cytokines have also been found to be elevated in bipolar mania. Several authors have demonstrated an elevation of TNF- $\alpha$ levels, ${ }^{99,100}$ and two studies demonstrated an increase in soluble TNF receptor 1 although they failed to replicate the finding of increased TNF- $\alpha .{ }^{101,102}$ Similarly, several authors have documented increased IL-6 during a manic phase of bipolar illness. ${ }^{98,99,103}$ Elevations in pro-inflammatory cytokines are not restricted to the manic state as TNF- $\alpha$ was increased in both manic and depressed patients, ${ }^{99}$ a finding also reported for IL-6. ${ }^{103}$ Other authors have demonstrated elevations in the production of proinflammatory cytokines and CRP as a trait marker of BD, independent of the current psychopathological state. ${ }^{104-106}$ Earlier studies had also demonstrated raised levels of serum sIL-2R among rapid cycling ${ }^{107}$ and manic ${ }^{108}$ bipolar patients with normalization in remission. ${ }^{107-109}$ In contrast, some studies found no significant association between pro-inflammatory cytokines and BD regardless of current state. ${ }^{102,110-112}$

A dysregulation of the production of anti-inflammatory cytokines IL-4 and IL-10 has also been implicated in BD. For example, it was reported that IL-10 is increased in patients with BD irrespective of the current psychopathological state. ${ }^{100,106,112}$ However, studies in cohorts of exclusively manic $^{96,97}$ or euthymic ${ }^{113}$ patients found no significant association with IL-10 levels. ${ }^{99,111}$ In support of an increase in anti-inflammatory cytokines in $\mathrm{BD}$, elevated levels of the anti-inflammatory cytokine IL-4 were repeatedly reported in both the manic and euthymic states of bipolar illness. ${ }^{98,103,113}$ In contrast, an ex-vivo examination of IL-4 could not find an association with mania. ${ }^{97}$

Beyond the investigation of inflammatory proteins as markers of diagnostic subtypes of BD, these immunological factors appear to be positively correlated with the severity of bipolar symptoms. Although some reported that serum CRP was associated with scores of the Young Mania Rating Scale score, but not Hamilton Depression scale score, ${ }^{114}$ others found that a Young Mania Rating Scale score was positively correlated with IL-2 and IL-6, and the Hamilton Depression scale with IL- 6 only. ${ }^{103}$ These findings are not uncontested, however, as several other studies found no association between several of these markers (CRP, IL-6, IL-8, TNF- $\alpha$, IL-12 and IL-10) and symptom severity in BD. ${ }^{99,110,115}$

Beyond the innate immune markers discussed above, a recent study has demonstrated derangement of indices of adaptive immunity including T-cell subtypes and cytokines. ${ }^{111}$ An emerging body of literature proposes that disruptions of T-cell mediated immunity may interact with the aforementioned mechanisms of inflammatory markers and HPA axis to contribute to the progression of neuropsychiatric disorders. ${ }^{116,117}$ 


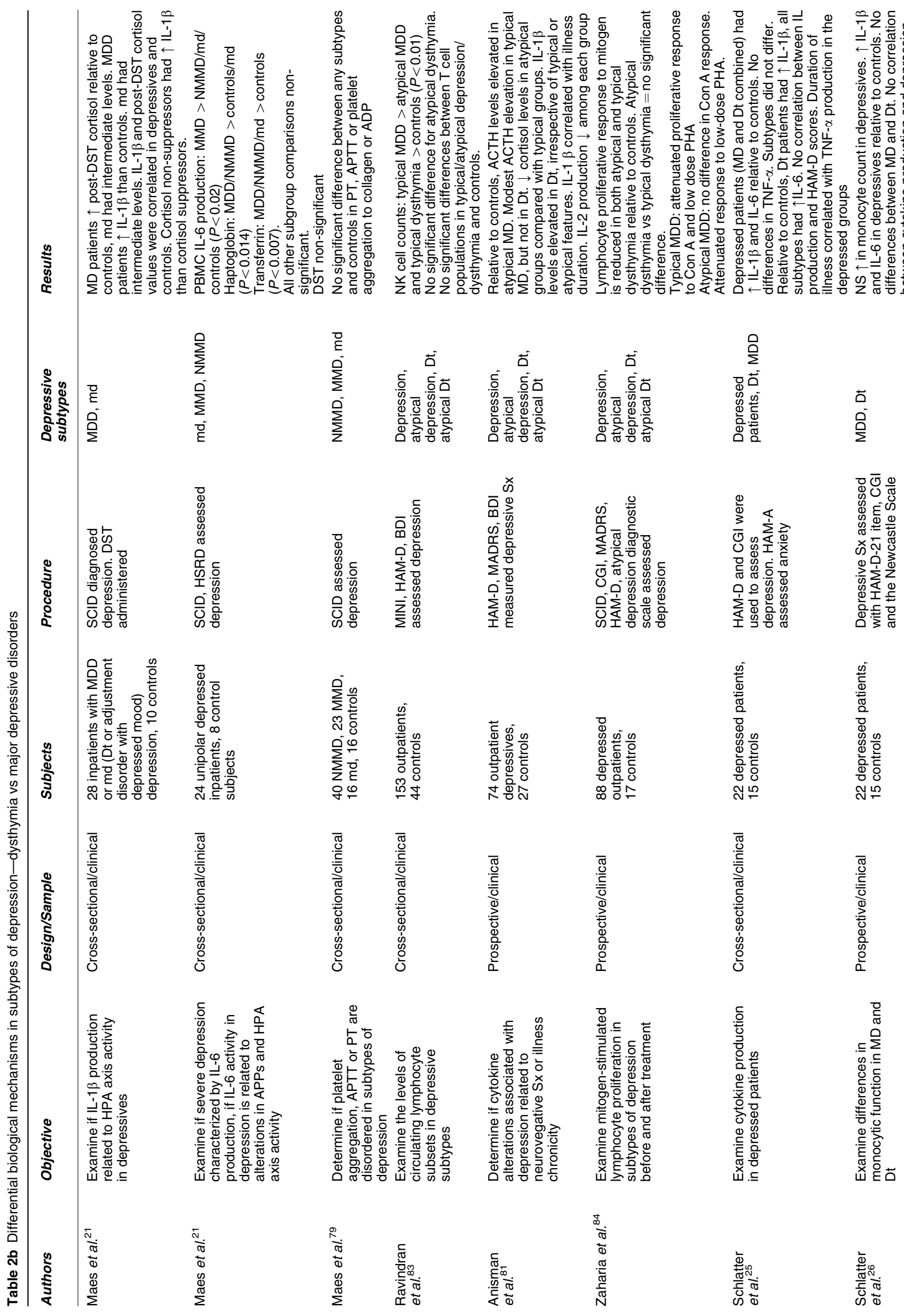




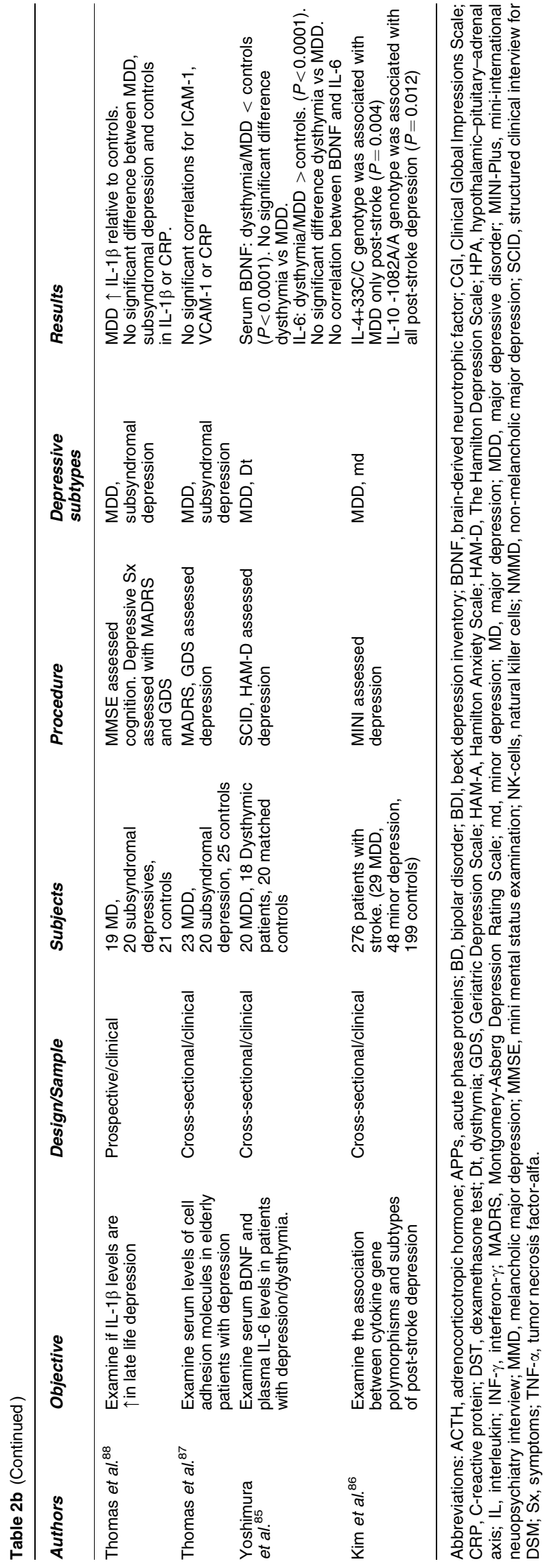

A key complication of studies in bipolar patients is the purported immune effects of lithium and other mood stabilizers. Several studies have demonstrated differences in immune parameters between lithium-treated patients and unmedicated patients, ${ }^{104,113,118}$ however, this effect is not always replicated. ${ }^{101,102,109,114}$ Any immune-modulatory effect appears to be related to chronic treatment with this agent and could not be replicated by in-vitro addition of lithium to samples from un-medicated patients. ${ }^{104}$ Additionally, it was suggested that the progressive nature of $\mathrm{BD}$ may act as a confounder as the early and late stages of the illness showed a differential profile of TNF- $\alpha$, IL- 6 and IL-10 expression. ${ }^{106}$

Several studies have reported dysfunction of the HPA axis in patients with BD. Similarly to unipolar depression, $\mathrm{BD}$ patients frequently demonstrate non-suppression of the cortisol response to DEX and/or corticotrophin releasing hormone in manic, ${ }^{119,120}$ mixed $^{120}$ and depressed states. ${ }^{121}$ It is notable, however, that the largest study of HPA axis functionality in BD did not find any significant difference in post-DEX cortisol between BD patients and controls. ${ }^{122}$ Overall, the study results remain inconclusive as both, a normalization $^{119,121}$ and a continued elevation ${ }^{123,124}$ of postDEX cortisol suppression was found in remitted BD patients.

$\mathrm{BD}$ has also been associated with increased basal cortisol levels ${ }^{119,122,124}$ and a greater cortisol awakening response and increased diurnal cortisol slope. ${ }^{122}$ In remission, though, basal cortisol secretion was not significantly different from controls, suggesting that this finding may be a marker of illness activity. ${ }^{125}$

It is also relevant to note that one study has demonstrated increased levels of serum von-Willebrand factor in patients with BD when compared with controls ${ }^{102}$ (Tables $2 \mathrm{~d}$ and 3 ).

Vascular depression. Vascular depression is associated with vascular disease, risk factors (e.g., diabetes mellitus, obesity) and late onset or change in the course of early-onset depression following the onset of vascular disease. ${ }^{126}$ The 'vascular depression' hypothesis proposed by Alexopoulos et al. ${ }^{126}$ suggests that characteristics of cerebrovascular disease and their risk factors are involved in the development of late-life depression. This hypothesis is based on the observed high comorbidity between depression and CVDs as well as risk factors such as hypertension, diabetes, coronary artery disease, stroke and the high rate of silent stroke and white matter hyperintensities among elderly individuals with depression. ${ }^{126-128}$ A study by Krishnan et al. $^{129}$ reported that the crude and adjusted risks for vascular depression were associated with age and late-onset depression. Clinical features in patients with vascular depression are characterized by significant loss of interests (apathy), cognitive dysfunction and psychomotor retardation. ${ }^{130}$ The degree of cognitive dysfunction observed in patients with vascular depression is usually greater than in patients with non-vascular depression. ${ }^{131}$ Causative factors of depression in the elderly are not well understood, though a role of biological risk factors, such as decreased arterial elasticity contributing to this late-life depression has been discussed. ${ }^{132}$

Decreased arterial elasticity, which is an important biological marker of atherosclerosis, has been observed in depressed patients. Arterial elasticity is an indication of an 


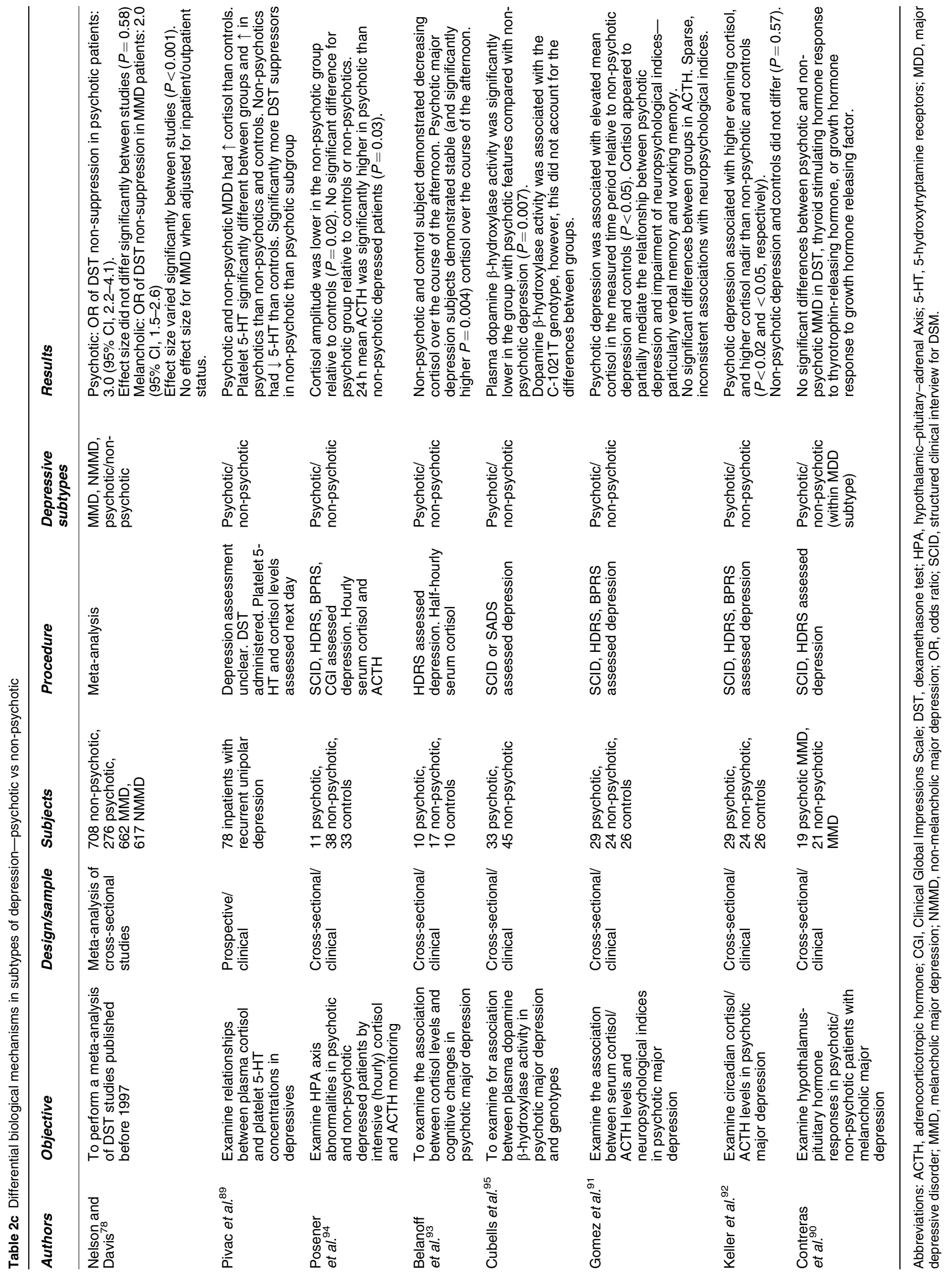




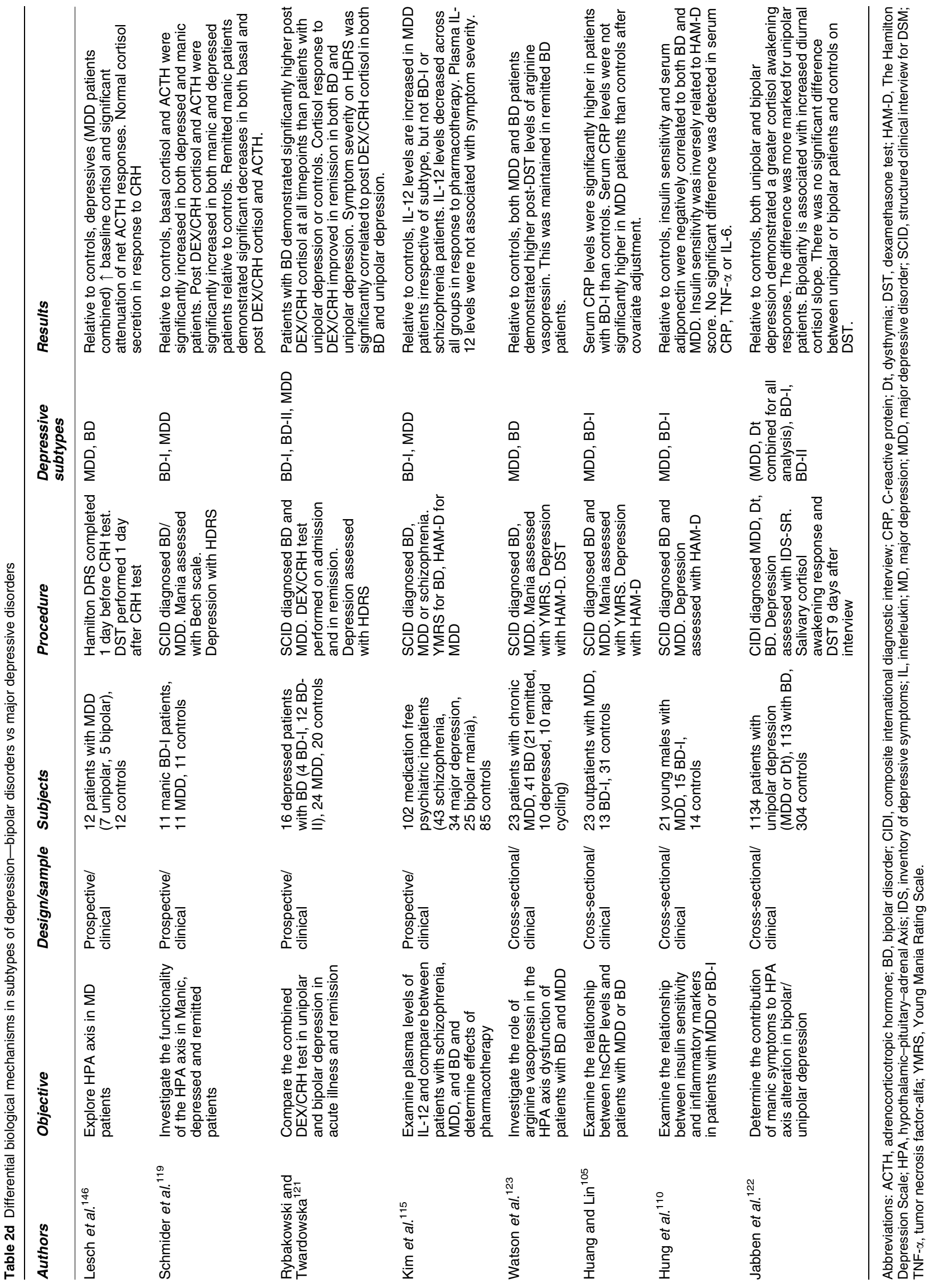




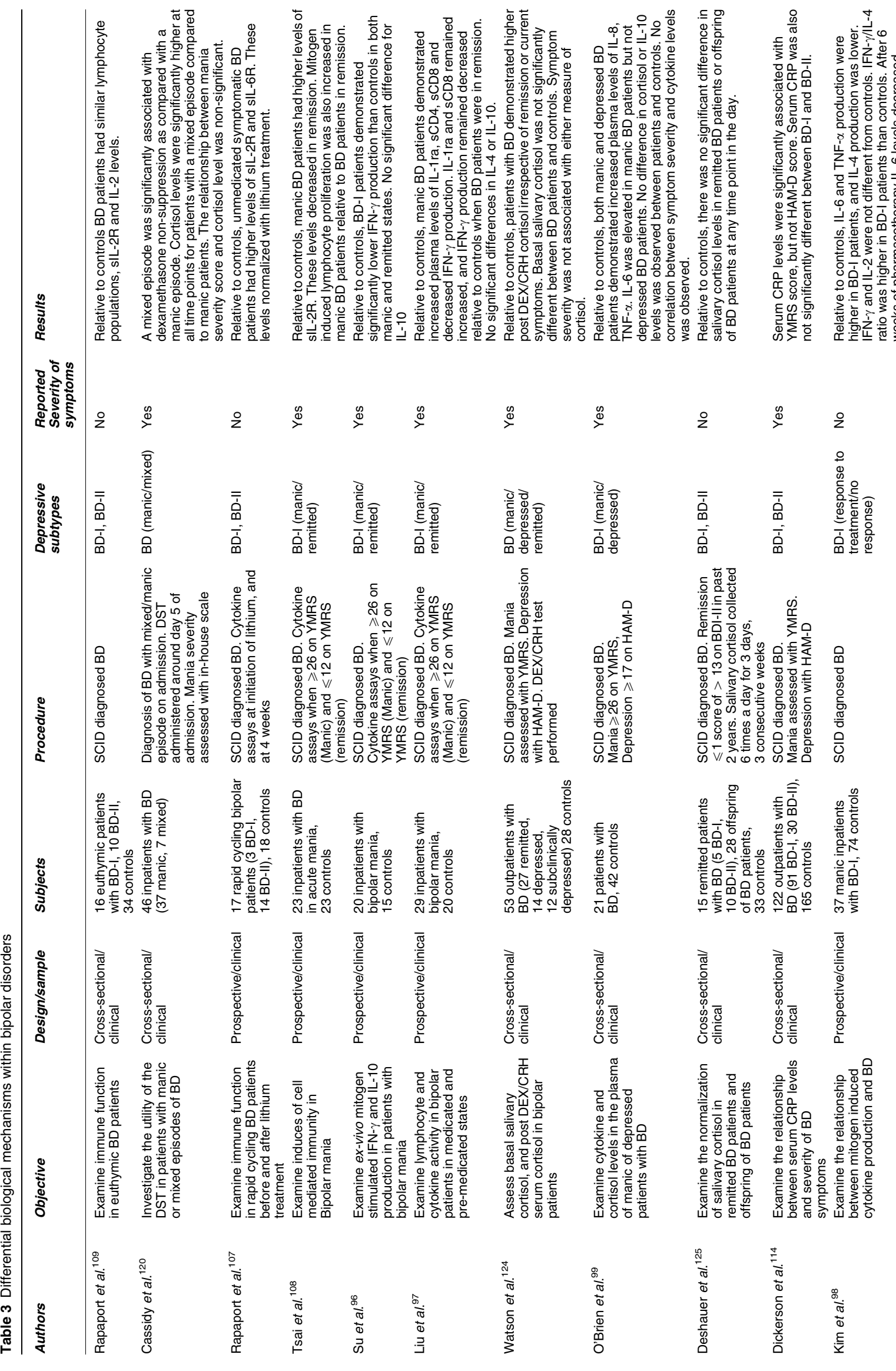




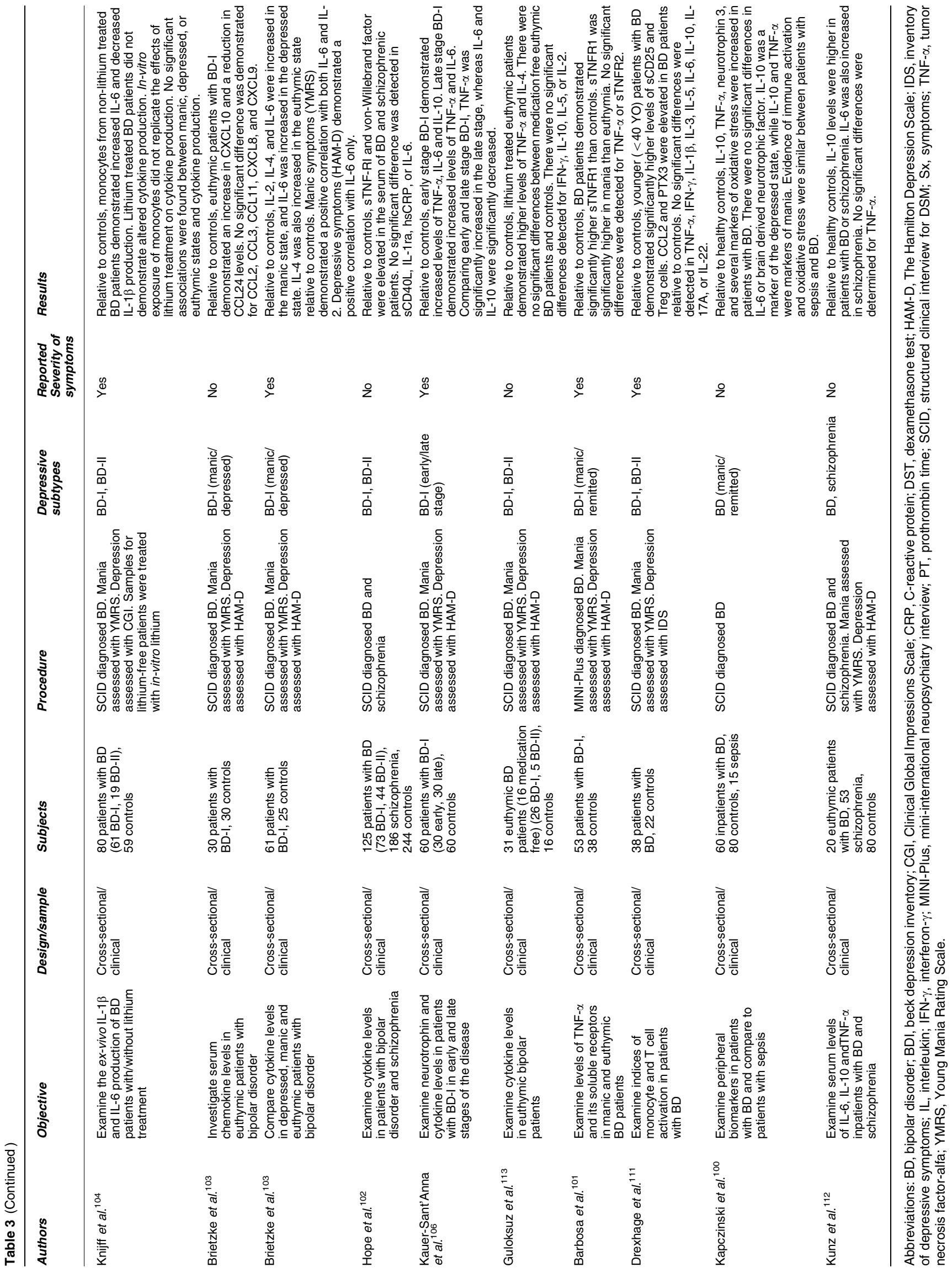


artery's structural and functional properties, that is, the artery's ability to stretch when under stress. ${ }^{133,134}$ Increased arterial stiffness (decreased arterial elasticity) is associated with cerebrovascular disease and death independent of atherosclerosis and other factors ${ }^{133,135-137}$ as well as with depression in the elderly. ${ }^{135}$ The strongest associations were seen among those who met the criteria for a DSM-IV depressive disorder (major or minor depression, or dysthymia) compared with those who reached a clinical level of depressive symptoms (CES-D score $\geqslant 16$ ) but did not meet the criteria for a depressive disorder. Those with a depressive disorder tended to have an increased risk for an abnormal distensibility coefficient of the common carotid artery and for an abnormal pulse wave velocity measurements, two markers of structural and functional vessel wall properties. ${ }^{138-140}$ Further studies support the hypothesis of arterial stiffness in depression. ${ }^{141}$ Arterial elasticity was examined in a sample of females with a lifetime DSM-IV-TR diagnosis of MD, currently depressed (onset $\leqslant 30$ days) with very severe depressive symptoms (HDRS-17 score $\geqslant 24$ ). Depressed patients had significantly higher baseline pulse wave velocity values relative to controls. Patients' pulse wave velocity and HDRS scores significantly decreased following a 6-week antidepressant treatment period. Significantly greater vascular improvements were seen among full responders to treatment (HDRS scores reduced by $\geqslant 50 \%$ ) as compared with partial responders indicating that patients' degree of improvement in arterial stiffness was related to the degree of reduction of depressive symptoms. Interestingly, clinical features such as illness duration, number of previous episodes, melancholic or psychotic features or electroconvulsive therapy did not alter the results. Taken together, these results suggest that clinically acute MDE may have a short-term effect on the vascular wall, which results in increased arterial stiffness possibly explaining some of the associations observed between CVD and depression. ${ }^{141}$

\section{Summary}

The association between CVDs and depression using the latter as a single diagnostic entity is well established and suggested to be bidirectional. ${ }^{5}$ With regard to subtypes of depression the association is less clear, but seems to vary in its strength by subtype. Also, reviews investigating if biological mechanisms implicated in the association between CVD and depression defined as a single entity would also apply to the various subtypes of depression are lacking. Thus, the aim of this review was to determine if a differential involvement of biological mechanisms for subtypes of depression is evident in the published literature and if so, if this contributes to explain differences in the strength of the association between CVD and depression subtypes.

This review suggests a dose-response relationship between the increasing severity of depressive symptoms and immune activation as well as HPA axis hyperactivity. It also found evidence that these two mechanisms are differently involved in the relationship with CVD depending upon depression subtype. ${ }^{20,21,24,25,72,81,88,89,142,143}$ However, the identification of a subtype-specific functional pattern for both mechanisms is not possible at this stage as study results are inconsistent. Other mechanisms such as arterial stiffness or endothelial dysfunction, which also are involved in the relationship between the disease entity depression and CVDs have not been investigated in subtypes of depression, with the notable exemption of $\mathrm{BD} .{ }^{66}$ The inconsistent study results are likely to be explained by the respective studies' limitations in terms of design factors and inconsistent methodologies. Many of the studies investigating biological mechanisms used samples that were small in number and heterogeneous in clinical and demographic participant characteristics such as severity of symptoms, duration of illness, number of comorbidities and histories of pharmacological and psychological therapies. They also varied significantly in the instruments and criteria used to classify depression, and techniques utilized in the measurement of biological markers. Another problem in the comparison of results is the variation in the delay between occurrence of CVD and assessment of depression and the heterogeneity in severity of CVDs. The paucity of longitudinal studies with a repeated assessment of both disease status is another limitation of reported studies.

On the other hand, and despite some overlap, the group of 'CVDs' is also heterogeneous with different clinical characteristics, risk factors and prognoses. The vast majority of studies examined myocardial infarction as an endpoint within the group of CVDs when studying the association with depression, and the number of studies reporting on other cardiovascular endpoints is considerably smaller. At least two of the biological mechanisms described above, arterial stiffness and endothelial dysfunction, are established steps in the pathophysiological cascade of disease development and could be considered endpoints in themselves. Thus, for a better understanding of a causal relationship it is not only necessary to differentiate between subtypes of depression but also between cardiovascular endpoints. An alternative approach for the latter is the analysis of the relationships of subtypes of depression with subclinical disease, for example, intimamedia-thickness or vascular brain lesions such as white matter lesions and lacunar infarcts, or, to study the association between subtypes of depression and specific biological mechanisms directly. The latter is possible for some of the discussed mechanisms, for example, arterial stiffness, endothelial dysfunction and to some extent the activation of the immune system and dysfunction of the HPA axis. These analyses, however, have to be prospective in design with repeated assessments of the clinical disease status as well as the subclinical or biological surrogates. The differences in the strength of associations between specific subtypes of depression and CVDs, as reported in the literature, suggests that different biological mechanisms might be involved in mediating these associations. This assumption would enable researchers to describe distinct (patho-) physiological profiles for subtypes of depression.

The implications for psychological treatment in reducing CVD mortality have also been raised. It has been suggested that if depression does indeed cause an increase in CVD mortality, then one would expect to see a reduction in mortality following psychological intervention. However, recent studies have not confirmed this expectation. ${ }^{144,145}$ Additionally, although depression may be a factor that predisposes a patient to the development of CVD, it may not necessarily be 
the factor that maintains the development of CVD. Systemic immune activation may be stimulated by one depressive episode and ongoing regardless of the episode going into remission through treatment. Very little research has investigated inflammation and depression longitudinally. Moreover, a different concept may be required for elderly patients among whom vascular depression is commonly seen.

A concept that applies a differential model of CVD and depressive subtypes may be more appropriate compared with a unifying model of depression used in the past. Research moving beyond the unifying model and assessing both single CVDs and depressive subtypes longitudinally may enhance efforts to unravel causes and mechanisms of the bidirectional relationship between CVD and depression. Such research would potentially lead to the development of timely and appropriate measures for detection, prevention and treatment for CVD and depression.

\section{Conflict of interest}

The authors declare no conflict of interest.

Acknowledgements. The study is supported by a research grant from the German Ministry of Education and Research (BMBF).

1. Goldston K, Baillie AJ. Depression and coronary heart disease: a review of the epidemiological evidence, explanatory mechanisms and management approaches. Clin Psychol Rev 2008; 28: 288-306.

2. Frasure-Smith $\mathrm{N}$, Lesperance $\mathrm{F}$. Depression and cardiac risk: present status and future directions. Heart 2010; 96: 173-176.

3. Van der Kooy K, Van Hout H, Marwijk H, Marten H, Stehouwer C, Beekman A. Depression and the risk for cardiovascular diseases: systematic review and meta analysis. Int J Geriatr Psychiatry 2007; 22: 613-626.

4. Rudisch B, Nemeroff CB. Epidemiology of comorbid coronary artery disease and depression. Biol Psychiatry 2003; 54: 227-240.

5. Grippo AJ, Johnson AK. Biological mechanisms in the relationship between depression and heart disease. Neurosci Biobehav Rev 2002; 26: 941-962.

6. Maes M. Evidence for an immune response in major depression: a review and hypothesis. Prog Neuropsychopharmacol Biol Psychiatry 1995; 19: 11-38.

7. Joynt KE, Whellan DJ, O'Connor CM. Depression and cardiovascular disease: mechanisms of interaction. Biol Psychiatry 2003; 54: 248-261.

8. Dantzer R, O'Connor JC, Freund GG, Johnson RW, Kelley KW. From inflammation to sickness and depression: when the immune system subjugates the brain. Nat Rev Neurosci 2008; 9: 46-56.

9. Kronfol Z. Immune dysregulation in major depression: a critical review of existing evidence. Int J Neuropsychopharmacol 2002; 5: 333-343.

10. Lippi G, Montagnana M, Facaloro E, Franchini M. Mental depression and cardiovascular disease: a multifaceted, bidirectional association. Semin Thromb Hemost 2009; 35: 325-336.

11. Raison $\mathrm{CL}$, Capuron $\mathrm{L}$, Miller $\mathrm{AH}$. Cytokines sing the blues: inflammation and the pathogenesis of depression. Trends Immunol 2006; 27: 24-31.

12. Kop WJ, Gottdiener JS. The role of immune system parameters in the relationship between depression and coronary artery disease. Psychosom Med 2005; 67(Supplement 1): S37-S41.

13. Brown ES, Varghese FP, McEwen BS. Association of depression with medical illness: does cortisol play a role? Biol Psychiatry 2004; 55: 1-9.

14. Grippo AJ, Johnson AK. Stress, depression and cardiovascular dysregulation: a review of neurobiological mechanisms and the integration of research from preclinical disease models. Stress 2009; 12: 1-21.

15. Association AP. Diagnostic and Statistical Manual of Mental Disorders, 4th edn, Text Revision 2000, American Psychiatric Association: Arlington, VA.

16. Baune BT, Adrian I, Arolt V, Berger K. Associations between major depression, bipolar disorders, dysthymia and cardiovascular diseases in the general adult population. Psychother Psychosom 2006; 75: 319-326.

17. Goldstein BI, Fagiolini A, Houck P, Kupfer DJ. Cardiovascular disease and hypertension among adults with bipolar I disorder in the United States. Bipolar Dis 2009; 11: 657-662.

18. Herbst S, Pietrazak R, Wagner J, White W, Petry N. Lifetime major depression is associated with coronary heart disease in older adults: results from the national epidemiologic survey on alcohol and related conditions. Psychosom Med 2007; 69: 729-734.

19. Larson S, Owens P, Ford D, Eaton W. Depressive disorder, dysthymia, and risk of stroke: thirteen-year follow-up from the baltimore epidemiologic catchment area study. Stroke 2001; 32: 1979-1983.

20. Maes M, Bosmans E, Meltzer HY, Scharpe S, Suy E. Interleukin-1 $\beta$ : a putative mediator of HPA axis hyperactivity in major depression? Am J Psychiatry 1993; 150: 1189-1193.

21. Maes M, Scharpe S, Meltzer H, Bosmans E, Suy E, Calabrese J et al. Relationships between interleukin- 6 activity, acute phase proteins, and function of the hypothalamic-pituitary-adrenal axis in severe depression. Psychiatry Res 1993; 49: 11-27.

22. Osby U, Brandt L, Correia N, Ekbom A, Sparen P. Excess mortality in bipolar and unipolar disorder in Sweden. Arch Gen Psychiatry 2001; 58: 844-850.

23. Penninx B, Beekman A, Honig A, Deeg D, Schoevers R, Eijk JV et al. Depression and cardiac mortality: results from a community-based longitudinal Study. Arch Gen Psychiatry 2001; 58: 221-227.

24. Rothermundt M, Arolt V, Fenker J, Gutbrodt $\mathrm{H}$, Peters $\mathrm{M}$, Kirchner $\mathrm{H}$. Different immune patterns in melancholic and non-melancholic major depression. Eur Arch Psychiatry Clin Neurosci 2001; 251: 90-97.

25. Schlatter J, Ortuño F, Cervera-Enguix S. Differences in interleukins' patterns between dysthymia and major depression. Eur Psychiatry 2001; 16: 317-319.

26. Schlatter J, Ortuño F, Cervera-Enguix S. Monocytic parameters in patients with dysthymia versus major depression. J Affect Dis 2004; 78: 243-247.

27. Callaghan RC, Khizar A. The incidence of cardiovascular morbidity among patients with bipolar disorder: a population-based longitudinal study in Ontario, Canada. J Affect Dis 2010; 122: 118-123.

28. Moher D, Liberati A, Tetzlaff J, Altman DG. Preferred reporting items for systematic reviews and meta-analyses: the PRISMA statement. BMJ 2009; 339: b2535.

29. Wassertheil-Smoller S, Applegate W, Berge K, Chang C, Davis B, Grimm R et al. Change in depression as a precursor of cardiovascular events. Arch Inter Med 1996; 156 : 553-561

30. Everson SA, Roberts RE, Goldberg D, Kaplan G. Depressive symptoms and increased risk of stroke mortality over a 29-year period. Arch Inter Med 1998; 158: 1133-1138.

31. Ariyo AA, Haan M, Tangen CM, Rutledge JC, Cushman M, Dobs A et al. Depressive symptoms and risks of coronary heart disease and mortality in elderly Americans. Circulation 2000; 102: 1773-1779.

32. Abramson J, Berger A, Krumholz HM, Vaccarino V. Depression and risk of heart failure among older persons with isolated systolic hypertension. Arch Intern Med 2001; 161: $1725-1730$.

33. Williams SA, KasI SV, Heiat A, Abramson JL, Krumholz HM, Vaccarino V. Depression and risk of heart failure among the elderly: a prospective community-based study. Psychosom Med 2002; 64: 6-12.

34. Everson-Rose SA, House JS, Mero RP. Depressive symptoms and mortality risk in a national sample: confounding effects of health status. Psychosom Med 2004; 66: 823-830.

35. Gump BB, Matthews KA, Eberly LE, Chang Y-f, for the MRG. Depressive symptoms and mortality in men: results from the multiple risk factor intervention trial. Stroke 2005; $\mathbf{3 6}$ : $98-102$

36. Wulsin LR, Evans JC, Vasan RS, Murabito JM, Kelly-Hayes M, Benjamin EJ. Depressive symptoms, coronary heart disease, and overall mortality in the Framingham heart study. Psychosom Med 2005; 67: 697-702.

37. Ahto M, Isoaho R, Puolijoki H, Vahlberg T, Kivela S-L. Stronger symptoms of depression predict high coronary heart disease mortality in older men and women. Int J Geriatr Psychiatry 2006; 22: 757-763.

38. Surtees PG, Wainwright NWJ, Luben RN, Wareham NJ, Bingham SA, Khaw K-T. Depression and ischemic heart disease mortality: evidence from the Epic-Norfolk United Kingdom prospective cohort study. Am J Psychiatry 2008; 165: 515-523.

39. Kendler K, Gardner C, Riske A, Gatz M. Major depression and coronary artery disease in the swedish twin registry. Arch Gen Psychiatry 2009; 66: 857-863.

40. Rugulies R. Depression as a predictor for coronary heart disease. a review and metaanalysis. Am J Prev Med 2002; 23: 51-61.

41. Wulsin LR, Singal BM. Do depressive symptoms increase the risk for the onset of coronary disease? A systematic quantitative review. Psychosom Med 2003; 65: 201-210.

42. Nicholson $\mathrm{A}$, Kuper $\mathrm{H}$, Hemingway $\mathrm{H}$. Depression as an aetiologic and prognostic factor in coronary heart disease: a meta-analysis of 6362 events among 146538 participants in 54 observational studies. Eur Heart J 2006; 27: 2763-2774.

43. Lauzon C, Beck CA, Huynh T, Dion D, Racine N, Carignan S et al. Depression and prognosis following hospital admission because of acute myocardial infarction. CMAJ 2003; 168: 547-552.

44. Frasure-Smith N, Lesperance F, Talajic M. Depression following myocardial infarction: impact on 6-month survival. JAMA 1993; 270: 1819-1825.

45. Frasure-Smith N, Lesperance F, Talajic M. Depression and 18-month prognosis after myocardial infarction. Circulation 1995; 91: 999-1005.

46. Carney R, Rich M, Freedland K, Saini J, teVelde A, Simeone C et al. Major depressive disorder predicts cardiac events in patients with coronary artery disease. Psychosom Med 1988; 50: 627-633. 
47. Barefoot JC, Helms MJ, Mark DB, Blumenthal JA, Califf RM, Haney TL et al. Depression and long-term mortality risk in patients with coronary artery disease. Am J Cardiol 1996; 78: 613-617.

48. Lespérance $F$, Frasure-Smith $N$, Juneau $M$, Theroux $P$. Depression and 1-year prognosis in unstable angina. Arch Inter Med 2000; 160: 1354-1360.

49. Rutledge T, Reis S, Olson M, Owens J, Kelsey S, Pepine C et al. Depression symptom severity and reported treatment history in the prediction of cardiac risk in women with suspected myocardial ischemia. Arch Gen Psychiatry 2006; 63: 874-880.

50. Whooley MA, de Jonge P, Vittinghoff E, Otte C, Moos R, Carney RM et al. Depressive symptoms, health behaviors, and risk of cardiovascular events in patients with coronary heart disease. JAMA 2008; 300: 2379-2388.

51. Barth J, Schumacher M, Herrmann-Lingen C. Depression as a risk factor for mortality in patients with coronary heart disease: a meta-analysis. Psychosom Med 2004; 66: 802-813.

52. van Melle JP, de Jonge P, Spijkerman TA, Tijssen JG, Ormel J, van Veldhuisen DJ et al. Prognostic association of depression following myocardial infarction with mortality and cardiovascular events: a meta-analysis. Psychosom Med 2004; 66: 814-822.

53. Meijer A, Conradi HJ, Bos EH, Thombs BD, van Melle JP, de Jonge P. Prognostic association of depression following myocardial infarction with mortality and cardiovascular events: a meta-analysis of 25 years of research. Gen Hosp Psychiatry 2011; 33: 203-216.

54. Williams LS, Ghose SS, Swindle RW. Depression and other mental health diagnoses increase mortality risk after ischemic stroke. Am J Psychiatry 2004; 161: 1090-1095.

55. Skala JA, Freedland KE, Carney RM. Coronary heart disease and depression: a review of recent mechanistic research. Can J Psychiatry 2006; 51: 738-745.

56. Stuart MJ, Baune BT. Depression and type 2 diabetes: inflammatory mechanisms of a psychoneuroendocrine co-morbidity. Neurosci Biobehav Rev 2012; 36: 658-676.

57. Dowlati Y, Herrmann N, Swardfager W, Liu H, Sham L, Reim EK et al. A meta-analysis of cytokines in major depression. Biol Psychiatry 2010; 67: 446-457.

58. Maes M. Depression is an inflammatory disease, but cell-mediated immune activation is the key component of depression. Prog Neuropsychopharmacol Biol Psychiatry 2011; 35: 664-675.

59. Paz-Filho G, Licinio J, Wong ML. Pathophysiological basis of cardiovascular disease and depression: a chicken-and-egg dilemma. Revista brasileira de psiquiatria 2010; 32: 181-191.

60. Hansson GK, Hermansson A. The immune system in atherosclerosis. Nat Immunol 2011; 12: 204-212.

61. Petaja J. Inflammation and coagulation. An overview. Thromb Res 2011; 127(Suppl 2): S34-S37.

62. Sasayama D, Hori H, lijima Y, Teraishi T, Hattori K, Ota M et al. Modulation of cortisol responses to the DEX/CRH test by polymorphisms of the interleukin-1beta gene in healthy adults. Behav Brain Functions: BBF 2011; 7: 23.

63. Malpas SC. Sympathetic nervous system overactivity and its role in the development of cardiovascular disease. Physiol Rev 2010; 90: 513-557.

64. Kemp AH, Quintana DS, Gray MA, Felmingham KL, Brown K, Gatt JM. Impact of depression and antidepressant treatment on heart rate variability: a review and metaanalysis. Biol Psychiatry 2010; 67: 1067-1074.

65. Shimokawa H. Primary endothelial dysfunction: atherosclerosis. J Mol Cell Cardiol 1999; 31: 23-37.

66. Rybakowski J, Wykretowicz A, Heymann-Szlachcinska A, Wysocki H. Impairment of endothelial function in unipolar and bipolar depression. Biol Psychiatry 2006; 60: 889-891.

67. Bonetti PO, Lerman LO, Lerman A. Endothelial dysfunction: a marker of atherosclerotic risk. Arterioscler Thromb Vasc Biol 2002; 22: 1065-1074.

68. Cooper DC, Tomfohr LM, Milic MS, Natarajan L, Bardwell WA, Ziegler MG et al. Depressed mood and flow-mediated dilation: a systematic review and meta-analysis. Psychosom Med 2011; 73: 360-369.

69. Rajagopalan S, Brook R, Rubenfire M, Pitt E, Young E, Pitt B. Abnormal brachial artery flow-mediated vasodilation in young adults with major depression. Am J Cardiol 2001; 88: 196-198.

70. Sherwood A, Hinderliter AL, Watkins LL, Waugh RA, Blumenthal JA. Impaired endothelial function in coronary heart disease patients with depressive symptomatology. J Am Coll Cardiol 2005; 46: 656-659.

71. Huang TL, Lee CT. T-helper 1/T-helper 2 cytokine imbalance and clinical phenotypes of acute-phase major depression. Psychiatry Clin Neurosci 2007; 61: 415-420.

72. Kaestner F, Hettich M, Peters M, Sibrowski W, Hetzel G, Ponath G et al. Different activation patterns of proinflammatory cytokines in melancholic and non-melancholic major depression are associated with HPA axis hyperactivity. J Affect Dis 2005; 87: 305-311.

73. Maes M, Mihaylova I, Kubera M, Ringel K. Activation of cell-mediated immunity in depression: association with inflammation, melancholia, clinical staging and the fatigue and somatic symptom cluster of depression. Prog Neuropsychopharmacology Biol Psychiatry 2012; 36: 169-175.

74. Marques-Deak AH, Neto FL, Dominguez WV, Solis AC, Kurcgant D, Sato F et al. Cytokine profiles in women with different subtypes of major depressive disorder. J Psychiatr Res 2007; 41: 152-159.

75. Rothermundt M, Arolt V, Peters M, Gutbrodt H, Fenker J, Kersting A et al. Inflammatory markers in major depression and melancholia. J Affect Dis 2001; 63: 93-102.
76. Erdem M, Celik C, Cayci T, Ozdemir B, Kurt YG, Akgul EO et al. Serum haptoglobin levels in patients with melancholic and nonmelancholic major depression. Prog Neuropsychopharmacology Biol Psychiatry 2011; 35: 944-947.

77. Schlatter J, Ortuno F, Cervera-Enguix S. Lymphocyte subsets and lymphokine production in patients with melancholic versus nonmelancholic depression. Psychiatry Res 2004; 128: $259-265$.

78. Nelson JC, Davis JM. DST studies in psychotic depression: a meta-analysis. Am J Psychiatry 1997; 154: 1497-1503.

79. Maes M, Van der Planken M, Van Gastel A, Desnyder R. Blood coagulation and platelet aggregation in major depression. $J$ Affect Dis 1996; 40: 35-40.

80. Yoon HK, Kim YK, Lee HJ, Kwon DY, Kim L. Role of cytokines in atypical depression. Nordic J Psychiatry, advance online publication, 22 September 2011 (e-pub ahead of print).

81. Anisman H, Ravindran A, Griffiths J, Merali Z. Endocrine and cytokine correlates of major depression and dysthymia with typical or atypical features. Mol Psychiatry 1999; 4 : 182-188.

82. Gecici O, Kuloglu M, Atmaca M, Tezcan AE, Tunckol H, Emul HM et al. High serum leptin levels in depressive disorders with atypical features. Psychiatry Clin Neurosci 2005; 59: 736-738.

83. Ravindran AV, Griffiths J, Merali Z, Anisman H. Circulating lymphocyte subsets in major depression and dysthymia with typical or atypical features. Psychosom Med 1998; 60: 283-289.

84. Zaharia MD, Ravindran AV, Griffiths J, Merali Z, Anisman H. Lymphocyte proliferation among major depressive and dysthymic patients with typical or atypical features. J Affect Dis 2000; 58: 1-10.

85. Yoshimura R, Umene-Nakano W, Hoshuyama T, Ikenouchi-Sugita A, Hori H, Katsuki A et al. Plasma levels of brain-derived neurotrophic factor and interleukin-6 in patients with dysthymic disorder: comparison with age- and sex-matched major depressed patients and healthy controls. Hum Psychopharmacol 2010; 25: 566-569.

86. Kim JM, Stewart R, Kim SW, Shin IS, Kim JT, Park MS et al. Associations of cytokine gene polymorphisms with post-stroke depression. World J Biol Psychiatry, advance online publication, 27 July 2011 (e-pub ahead of print).

87. Thomas AJ, Morris C, Davis S, Jackson E, Harrison R, O'Brien JT. Soluble cell adhesion molecules in late-life depression. Int Psychogeriatr 2007; 19: 914-920.

88. Thomas AJ, Davis S, Morris C, Jackson E, Harrison R, O'Brien JT. Increase in interleukin1beta in late-life depression. Am J Psychiatry 2005; 162: 175-177.

89. Pivac N, Jakovljevic M, Muck-Seler D, Brzovic Z. Hypothalamic-pituitary-adrenal axis function and platelet serotonin concentrations in depressed patients. Psychiatry Res 1997; 73: 123-132.

90. Contreras F, Menchon JM, Urretavizcaya M, Navarro MA, Vallejo J, Parker G. Hormonal differences between psychotic and non-psychotic melancholic depression. J Affect Dis 2007; 100: 65-73.

91. Gomez RG, Fleming SH, Keller J, Flores B, Kenna H, DeBattista C et al. The neuropsychological profile of psychotic major depression and its relation to cortisol. Biol Psychiatry 2006; 60: 472-478.

92. Keller J, Flores B, Gomez RG, Solvason HB, Kenna H, Williams GH et al. Cortisol circadian rhythm alterations in psychotic major depression. Biol Psychiatry 2006; 60: 275-281.

93. Belanoff JK, Kalehzan M, Sund B, Fleming Ficek SK, Schatzberg AF. Cortisol activity and cognitive changes in psychotic major depression. Am J Psychiatry 2001; 158: 1612-1616.

94. Posener JA, DeBattista C, Williams GH, Chmura Kraemer H, Kalehzan BM, Schatzberg AF. 24-Hour monitoring of cortisol and corticotropin secretion in psychotic and nonpsychotic major depression. Arch Gen Psychiatry 2000; 57: 755-760.

95. Cubells JF, Price LH, Meyers BS, Anderson GM, Zabetian CP, Alexopoulos GS et al. Genotype-controlled analysis of plasma dopamine beta-hydroxylase activity in psychotic unipolar major depression. Biol Psychiatry 2002; 51: 358-364.

96. Su KP, Leu SJ, Yang YY, Shen WW, Chou YM, Tsai SY. Reduced production of interferon-gamma but not interleukin-10 in bipolar mania and subsequent remission. $J$ Affect Disord 2002; 71: 205-209.

97. Liu HC, Yang YY, Chou YM, Chen KP, Shen WW, Leu SJ. Immunologic variables in acute mania of bipolar disorder. J Neuroimmunol 2004; 150: 116-122.

98. Kim YK, Jung HG, Myint AM, Kim H, Park SH. Imbalance between pro-inflammatory and anti-inflammatory cytokines in bipolar disorder. J Affect Disord 2007; 104: 91-95.

99. O'Brien SM, Scully P, Scott LV, Dinan TG. Cytokine profiles in bipolar affective disorder: focus on acutely ill patients. J Affect Disord 2006; 90: 263-267.

100. Kapczinski F, Dal-Pizzol F, Teixeira AL, Magalhaes PV, Kauer-Sant'Anna M, Klamt F et al. Peripheral biomarkers and illness activity in bipolar disorder. J Psychiatr Res 2011; 45: 156-161.

101. Barbosa IG, Huguet RB, Mendonca VA, Sousa LP, Neves FS, Bauer ME et al. Increased plasma levels of soluble TNF receptor I in patients with bipolar disorder. Eur Arch Psychiatry Clin Neurosci 2011; 261: 139-143.

102. Hope S, Melle I, Aukrust P, Steen NE, Birkenaes AB, Lorentzen S et al. Similar immune profile in bipolar disorder and schizophrenia: selective increase in soluble tumor necrosis factor receptor I and von Willebrand factor. Bipolar Disord 2009; 11: 726-734.

103. Brietzke E, Stertz L, Fernandes BS, Kauer-Sant'anna M, Mascarenhas M, Escosteguy Vargas $A$ et al. Comparison of cytokine levels in depressed, manic and euthymic patients with bipolar disorder. J Affect Disord 2009; 116: 214-217. 
104. Knijff EM, Breunis MN, Kupka RW, de Wit HJ, Ruwhof C, Akkerhuis GW et al. An imbalance in the production of IL-1beta and IL-6 by monocytes of bipolar patients: restoration by lithium treatment. Bipolar Disord 2007; 9: 743-753.

105. Huang TL, Lin FC. High-sensitivity C-reactive protein levels in patients with major depressive disorder and bipolar mania. Prog Neuropsychopharmacol Biol Psychiatry 2007; 31: 370-372.

106. Kauer-Sant'Anna M, Kapczinski F, Andreazza AC, Bond DJ, Lam RW, Young LT et al. Brain-derived neurotrophic factor and inflammatory markers in patients with early- vs. late-stage bipolar disorder. Int J Neuropsychopharmacol 2009; 12: 447-458.

107. Rapaport MH, Guylai L, Whybrow P. Immune parameters in rapid cycling bipolar patients before and after lithium treatment. J Psychiatr Res 1999; 33: 335-340.

108. Tsai SY, Chen KP, Yang YY, Chen CC, Lee JC, Singh VK et al. Activation of indices of cell-mediated immunity in bipolar mania. Biol Psychiatry 1999; 45: 989-994.

109. Rapaport MH. Immune parameters in euthymic bipolar patients and normal volunteers. $J$ Affect Disord 1994; 32: 149-156.

110. Hung YJ, Hsieh CH, Chen YJ, Pei D, Kuo SW, Shen DC et al. Insulin sensitivity, proinflammatory markers and adiponectin in young males with different subtypes of depressive disorder. Clin Endocrinol (Oxf) 2007; 67: 784-789.

111. Drexhage RC, Hoogenboezem TH, Versnel MA, Berghout A, Nolen WA, Drexhage HA. The activation of monocyte and $T$ cell networks in patients with bipolar disorder. Brain Behav Immun 2011; 25: 1206-1213.

112. Kunz M, Cereser KM, Goi PD, Fries GR, Teixeira AL, Fernandes BS et al. Serum levels of IL-6, IL-10 and TNF-alpha in patients with bipolar disorder and schizophrenia: differences in pro- and anti-inflammatory balance. Rev Bras Psiquiatr 2011; 33: 268-274.

113. Guloksuz S, Cetin EA, Cetin T, Deniz G, Oral ET, Nutt DJ. Cytokine levels in euthymic bipolar patients. J Affect Disord 2010; 126: 458-462.

114. Dickerson F, Stallings C, Origoni A, Boronow J, Yolken R. Elevated serum levels of C reactive protein are associated with mania symptoms in outpatients with bipolar disorder Prog Neuropsychopharmacol Biol Psychiatry 2007; 31: 952-955.

115. Kim YK, Suh IB, Kim H, Han CS, Lim CS, Choi SH et al. The plasma levels of interleukin12 in schizophrenia, major depression, and bipolar mania: effects of psychotropic drugs. Mol Psychiatry 2002; 7: 1107-1114

116. Lewitus GM, Wilf-Yarkoni A, Ziv Y, Shabat-Simon M, Gersner R, Zangen A et al. Vaccination as a novel approach for treating depressive behavior. Biol Psychiatry 2009; 65: 283-288.

117. Schwartz $M$, Shechter $R$. Protective autoimmunity functions by intracranial immunosurveillance to support the mind: the missing link between health and disease. Mol Psychiatry 2010; 15: 342-354.

118. Boufidou F, Nikolaou C, Alevizos B, Liappas IA, Christodoulou GN. Cytokine production in bipolar affective disorder patients under lithium treatment. J Affect Disord 2004; 82 309-313.

119. Schmider J, Lammers CH, Gotthardt U, Dettling M, Holsboer F, Heuser IJ. Combined dexamethasone/corticotropin-releasing hormone test in acute and remitted manic patients, in acute depression, and in normal controls: I. Biol Psychiatry 1995; 38 797-802.

120. Cassidy F, Ritchie JC, Carroll BJ. Plasma dexamethasone concentration and cortiso response during manic episodes. Biol Psychiatry 1998; 43: 747-754.

121. Rybakowski JK, Twardowska K. The dexamethasone/corticotropin-releasing hormone test in depression in bipolar and unipolar affective illness. J Psychiatr Res 1999; 33 363-370.

122. Jabben N, Nolen WA, Smit JH, Vreeburg SA, Beekman AT, Penninx BW. Co-occurring manic symptomatology influences HPA axis alterations in depression. $J$ Psychiatr Res 2011; 45: 1208-1213.

123. Watson S, Gallagher P, Ferrier IN, Young AH. Post-dexamethasone arginine vasopressin levels in patients with severe mood disorders. J Psychiatr Res 2006; 40: 353-359.

124. Watson S, Gallagher P, Ritchie JC, Ferrier IN, Young AH. Hypothalamic-pituitary-adrenal axis function in patients with bipolar disorder. Br J Psychiatry 2004; 184: 496-502.

125. Deshauer D, Duffy A, Meaney M, Sharma S, Grof P. Salivary cortisol secretion in remitted bipolar patients and offspring of bipolar parents. Bipolar Disord 2006; 8: 345-349.

126. Alexopoulos GS, Meyers BS, Young RC, Campbell S, Silbersweig D, Charlson M. 'Vascular depression' hypothesis. Arch Gen Psychiatry 1997; 54: 915-922.
127. O'Brien J, Desmond P, Ames D, Schweitzer I, Harrigan S, Tress B. A magnetic resonance imaging study of white matter lesions in depression and alzheimer's disease. $\mathrm{Br} J$ Psychiatry 1996; 168: 477-485.

128. Baldwin R, O'Brien J. Vascular basis of late-onset depressive disorder. Br J Psychiatry 2002; 180: 157-160.

129. Krishnan RRR, Hays JC, Blazer DG. MRI-defined vascular depression. Am J Psychiatry 1997; 154: 497-501.

130. Steffens DC, Helms MJ, Krishnan KRR, Burke GL. Cerebrovascular disease and depression symptoms in the cardiovascular health study. Stroke 1999; 30: 2159-2166.

131. Ramasubbu R. Relationship between depression and cerebrovascular disease: conceptual issues. J Affect Dis 2000; 57: 1-11.

132. Hickie I, Scott E. Late-onset depressive disorders: a preventablle variant of cerebrovascular disease? Psychol Med 1998; 28: 1007-1013.

133. Liao D. Arterial stiffness and the development of hypertension. Ann Med 2000; 32 : 383-385

134. Cockcoroft JR, Wilkinson IB, Webb DJ. Age, arterial stiffness and the endothelium. Age Ageing 1997; 26(suppl 4): 53-60.

135. Tiemeir H, Breteler M, Popele NMv, Hofman A, Witteman J. Late life depression is associated with arterial stiffness: a population-based study. J Am Geriatr Soc 2003; 51: $1105-1110$.

136. Laurent S, Boutouyroe P, Asmar R, Gautier I, Laloux B, Guize L et al. Aortic stiffness is an independent predicator of all - cause and cardiovascular mortality in hypertensive patients. Hypertension 2001; 15: 426-444.

137. Meaume S, Benetos A, Henry OF, Rudnichi A, Safar ME. Aortic pulse wave velocity predicts cardiovascular mortality in subjects $>70$ years of age. Arterioscler Thromb Vasc Biol 2001; 21: 2046-2050.

138. Naidu M, Reddy B, Yashmaina S, Patnaik A, Rani P. Validity and reproducibility of arterial pulse wave velocity measurement using new device with oscillometric technique: a pilot study. Biomed Eng Online 2005; 4: 49.

139. Simons PCG, Algra A, Bots ML, Grobbee DE, van der Graaf Y. Common carotid intimamedia thickness and arterial stiffness: indicators of cardiovascular risk in high-risk patients. The SMART Study (second manifestations of ARTerial disease). Circulation 1999; 100: 951-957.

140. Blacher J, Asmar R, Djane S, London GM, Safar ME. Aortic pulse wave velocity as a marker of cardiovascular risk in hypertensive patients. Hypertension 1999; 33: 1111-1117.

141. Oulis P, Kouzoupis A, Kyrkou K, Masdrakis VG, Georgiopoulos G, Karapoulios E et al. Reversal of increased arterial stiffness in severely depressed women after 6-week antidepressant treatment. J Affect Dis 2010; 122: 164-166.

142. Anisman $H$, Ravindran A, Griffiths J, Merali Z. Interleukin-1 $\beta$ production in dysthymia before and after pharmacotherapy. Biol Psychiatry 1999; 46: 1649-1655.

143. Owen BM, Eccleston D, Ferrier IN, Young H. Raised levels of plasma interleukin1\&\#x03B2; in major and postviral depression. Acta Psychiatrica Scandinavica 2001; 103: 226-228.

144. Dickens C, McGowan L, Percival C, Tomenson B, Cotter L, Heagerty A et al. Depression is a risk factor for mortality after myocardial infarction: fact or artifact? $\mathrm{J}$ Am Coll Cardiol 2007; 49: 1834-1840.

145. Rees K, Bennett P, West R, Smith GD, Ebrahim S. Psychological interventions for coronary heart disease (Review). Cochrane Database of Systematic Rev 2004; $1-63$

146. Lesch KP, Laux G, Schulte HM, Pfüller H, Beckmann H. Corticotropin and cortisol response to human $\mathrm{CRH}$ as a probe for HPA system integrity in major depressive disorder. Psychiatry Res 1988; 24: 25-34.

Translational Psychiatry is an open-access journal published by Nature Publishing Group. This work is licensed under the Creative Commons Attribution-Noncommercial-No Derivative Works 3.0 Unported License. To view a copy of this license, visit http://creativecommons.org/licenses/by-nc-nd/3.0/

\section{Supplementary Information accompanies the paper on the Translational Psychiatry website (http://www.nature.com/tp)}

